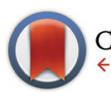

CrossMark

Cite this: Dalton Trans., 2016, 45 1208

Received 21st October 2015, Accepted 1st December 2015

DOI: $10.1039 / c 5 d t 04133 c$

www.rsc.org/dalton

\title{
Alcohol- and water-soluble bis(tpy)quaterthiophenes with phosphonium side groups: new conjugated units for metallo-supramolecular polymers $\uparrow$
}

P. Štenclová, K. Šichová, I. Šloufová, J. Zedník, J. Vohlídal* and J. Svoboda*

Bis(tpy)quaterthiophenes with symmetrically distributed two and four 6-bromohexyl side groups were prepared and modified by the reaction with triethylphosphine to give the corresponding ionic species. Both ionic and non-ionic bis(tpy)quaterthiophenes (unimers) were assembled with $\mathrm{Zn}^{2+}$ and $\mathrm{Fe}^{2+}$ ions to conjugated metallo-supramolecular polymers (MSPs), of which the ionic ones are soluble in alcohols and those derived from tetrasubstituted unimers are soluble even in water. The differences in assembly are specified between systems with (i) ionic and non-ionic unimers, (ii) $\mathrm{Zn}^{2+}$ and $\mathrm{Fe}^{2+}$ ion couplers, and (iii) methanol and water solvents. A substantial decrease in the stability of Fe-MSPs and a surprisingly high red shift of the luminescence band of Zn-MSPs were observed on going from methanol to aqueous solutions.

\section{Introduction}

Conjugated metallo-supramolecular polymers (MSPs) derived from $\alpha, \omega$-bis(tpy) oligoarylenes (tpy stands for 2,2':6', $2^{\prime \prime}$-terpyridine- $4^{\prime}$-yl end-group) are of interest as potential materials for devices with applications based on the light/electricity interconversion and non-linear optical phenomena (light-emitting devices, photovoltaic cells, etc.). ${ }^{1-16}$ However, an overwhelming majority of these MSPs suffer from low solubility, which makes their processing difficult. For example, MSPs derived from $\alpha, \omega$-bis(tpy)oligophenylenes have been processed from acids ${ }^{17,18}$ that surely are not optimal solvents.

Chains of conjugated MSPs of this type are composed of molecules of bisterpyridines that are linked via facial and meridian coordination of their tpy end-groups to metal ions such as $\mathrm{Ru}^{2+}, \mathrm{Fe}^{2+}, \mathrm{Zn}^{2+}$ and $\mathrm{Co}^{2+}$ (generally $\mathrm{Mt}^{2+}$ ) ions. The tpy- $\mathrm{Mt}^{2+}$-tpy linkages are strictly linear and rigid. ${ }^{11,19-27}$ The enchained unimers are also quite rigid due to the delocalization of $\pi$-electrons. The rigidity of both of these constitutional units together with electrostatic repulsions of the main-chain $\mathrm{Mt}^{2+}$ cations favor extended conformations of MSP chains that are favorable for inter-chain attraction. Thus the above struc-

Department of Physical and Macromolecular Chemistry, Charles University in Prague, Faculty of Science, Hlavova 2030, Prague 2, CZ-128 40, Czech Republic. E-mail: jiri.vohlidal@natur.cuni.cz, jan.svoboda@natur.cuni.cz;

Fax: +420 224919752; Tel: +420 221951310

$\dagger$ Electronic supplementary information (ESI) available. See DOI: 10.1039/ c5dt04133c tural features can be regarded as the main reason for the low solubility of MSPs derived from $\alpha, \omega$-bis (tpy)oligoarylenes.

An increase in the solubility of the discussed conjugated MSPs has been achieved by introducing pendant alkyl groups into unimer units. However, this increase is insufficient. ${ }^{28}$ Further improvement in the solubility of MSPs can be achieved by introducing cationic pendant groups onto unimer building blocks. The markedly cationic character of MSP chains should reduce the inter-chain attraction and thus make MSPs more soluble mainly in polar solvents such as alcohols or even in water. Such solvents are perhaps the most desired for processing of conjugated MSPs.

The above approach has been recently tested on thiophene and bithiophene with tpy end-groups. ${ }^{29}$ In the present paper, we report the preparation and basic properties of $\alpha, \omega$-bis(tpy)quaterthiophenes with cationic side groups and related conjugated MSPs with $\mathrm{Zn}^{2+}$ and $\mathrm{Fe}^{2+}$ ion couplers. Since the studied MSPs show constitutional dynamics, ${ }^{30,31}$ they exist in solutions as short oligomeric chains composed of starting unimers. The term unimer proposed by Ciferri $^{32}$ is used in the further text for a building block of MSPs.

\section{Results and discussion}

The prepared ionic as well as non-ionic unimers and their abbreviations are shown in Chart 1 together with the numbering of the central block positions and the marking of the rings used in the assignment of NMR spectra. The letter $\mathbf{Q}$ denotes 

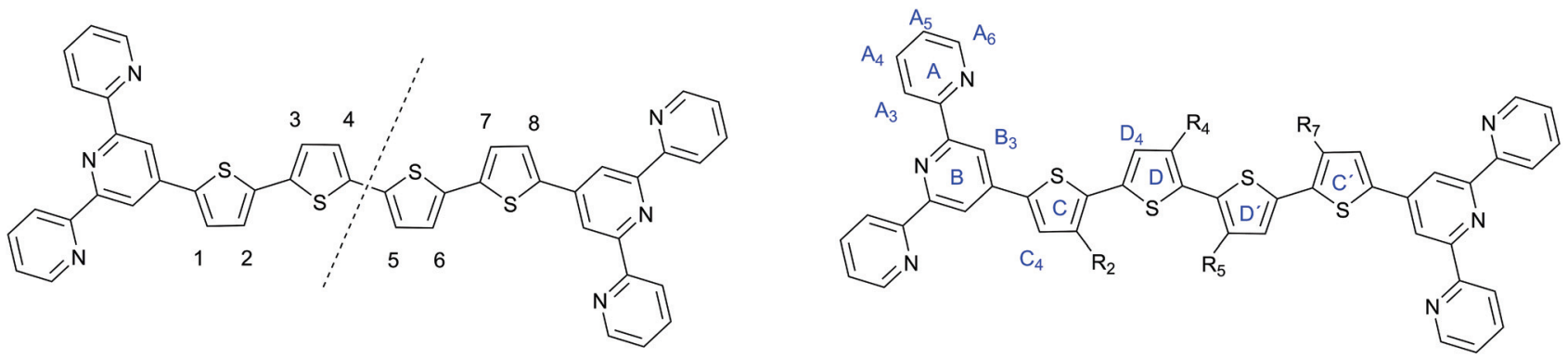

positions $1,3,6,8$ are occupied by hydrogen atoms in all structures

$$
\begin{array}{ll}
\text { Q } & \mathrm{R}_{2}, \mathrm{R}_{4}, \mathrm{R}_{5}, \mathrm{R}_{7}=\mathrm{H} \\
\text { Q27-H } & \mathrm{R}_{2}, \mathrm{R}_{7}=\left(\mathrm{CH}_{2}\right)_{5} \mathrm{CH}_{3} \quad \mathrm{R}_{4}, \mathrm{R}_{5}=\mathrm{H} \\
\text { Q27-A } & \mathrm{R}_{2}, \mathrm{R}_{7}=\left(\mathrm{CH}_{2}\right)_{6} \mathrm{OC}_{6} \mathrm{H}_{6} \mathrm{OCH}_{3} \quad \mathrm{R}_{2}, \mathrm{R}_{5}=\mathrm{H} \\
\text { Q27-Br } & \mathrm{R}_{2}, \mathrm{R}_{7}=\left(\mathrm{CH}_{2}\right)_{6} \mathrm{Br} \quad \mathrm{R}_{4}, \mathrm{R}_{5}=\mathrm{H} \\
\mathbf{Q 2 7 - P}^{+} & \mathrm{R}_{2}, \mathrm{R}_{7}=\left(\mathrm{CH}_{2}\right)_{6} \mathrm{P}^{+} \mathrm{Et}_{3} \mathrm{Br}^{-} \quad \mathrm{R}_{4}, \mathrm{R}_{5}=\mathrm{H}
\end{array}
$$

$\begin{array}{lll}\text { Q45-A } & \mathrm{R}_{2}, \mathrm{R}_{7}=\mathrm{H} \quad \mathrm{R}_{4}, \mathrm{R}_{5}=\left(\mathrm{CH}_{2}\right)_{6} \mathrm{OC}_{6} \mathrm{H}_{6} \mathrm{OCH}_{3} \\ \text { Q45-Br } & \mathrm{R}_{2}, \mathrm{R}_{7}=\mathrm{H} \quad \mathrm{R}_{4}, \mathrm{R}_{5}=\left(\mathrm{CH}_{2}\right)_{6} \mathrm{Br} \\ \text { Q45-P } & \mathrm{R}_{2}, \mathrm{R}_{7}=\mathrm{H} \quad \mathrm{R}_{4}, \mathrm{R}_{5}=\left(\mathrm{CH}_{2}\right)_{6} \mathrm{P}^{+} \mathrm{Et}_{3} \mathrm{Br}^{-} \\ \text {Q2457-A } & \mathrm{R}_{2}, \mathrm{R}_{4}, \mathrm{R}_{5}, \mathrm{R}_{7}=\left(\mathrm{CH}_{2}\right)_{6} \mathrm{OC}_{6} \mathrm{H}_{6} \mathrm{OCH}_{3} \\ \text { Q2457-Br } & \mathrm{R}_{2}, \mathrm{R}_{4}, \mathrm{R}_{5}, \mathrm{R}_{7}=\left(\mathrm{CH}_{2}\right)_{6} \mathrm{Br} \\ \text { Q2457-P } & \mathrm{R}_{2}, \mathrm{R}_{4}, \mathrm{R}_{5}, \mathrm{R}_{7}=\left(\mathrm{CH}_{2}\right)_{6} \mathrm{P}^{+} \mathrm{Et}_{3} \mathrm{Br}^{-}\end{array}$

Chart 1 Structures and codes of the prepared unimers.

the unimers with the quaterthiophene central block and the numbers behind it indicate the positions occupied by hexyl groups (suffix -H) or by hexyl groups capped with a 4-methoxyphenoxy group (suffix -A) or a bromine atom (suffix -Br) or a triethylphosphonium group (suffix $-\mathbf{P}^{+}$). MSPs are marked with the prefix $\mathbf{P}_{\mathbf{Z n}}$ (polymers with $\mathrm{Zn}^{2+}$ ion couplers) or $\mathbf{P}_{\mathbf{F e}}$ $\left(\mathrm{Fe}^{2+}\right.$ ion couplers) before the unimer label: for example, $\mathbf{P}_{\text {Zn }} \mathbf{Q}$ 27-Br denotes the MSPs formed by the assembly of $\mathrm{Zn}^{2+}$ ions and unimer Q27-Br that contains 6-bromohexyl groups attached to the quaterthiophene central block at positions 2 and 7; $\mathbf{P}_{\mathrm{Fe}} \mathbf{Q 4 5}-\mathbf{P}^{+}$stands for the MSPs formed from $\mathrm{Fe}^{2+}$ ions and unimer $\mathbf{Q 4 5}-\mathbf{P}^{+}$that contains two 6-(triethylphosphonium)hexyl groups attached to positions 4 and 5 of the central block, etc.

\section{Synthesis and characterization of unimers and polymers}

The reference unimers $\mathbf{Q}$ and $\mathbf{Q 2 7}-\mathbf{H}$ were prepared using the Suzuki-Miyaura coupling strategy (Scheme 1) and the conditions applied earlier. ${ }^{28,29,33} \mathbf{B r}$-unimers were prepared using the strategy shown in Schemes 1 and 2a. The starting monomer 3-[6-(4-methoxyphenoxy)hexyl]thiophene was prepared using the procedure described elsewhere. ${ }^{34}$ The procedure starting from 3-(6-bromohexyl)thiophene used for the synthesis of ionic unimers with mono- $(\mathbf{M})$ and bithiophene (B) central blocks ${ }^{29}$ was not so effective owing to low efficiency of purification of unimers with bromohexyl groups. Connecting tpy end-groups by Suzuki coupling (Scheme 1c) was accompanied by partial dehydrobromination of bromohexyl side groups promoted with tpy end-groups. ${ }^{29}$ Purification of short unimers could be done easily (for $\mathbf{M}$ ) or feasibly (for B), but the purification of bis(tpy)quaterthiophenes was almost impossible.

The use of new starting monomers avoided the above difficulties and, in addition, made the isolation of all intermediates as well as A-unimers much easier. The A-unimers were then allowed to react with $\mathrm{BBr}_{3}$ (Scheme 2a) to give the corresponding Br-unimers with bromohexyl side groups (yield $85-95 \%$ ), which were finally treated with triethylphosphine to give the corresponding ionic $\mathbf{P}^{+}$-unimers (Scheme $2 b$ ). Excess $\mathrm{PEt}_{3}$ was easily removed by vacuum distillation and its oxide $\left(\mathrm{POEt}_{3}\right)$ was washed away with toluene and ether. Solid products were isolated by centrifugation (yield of the ionization step was from 75 to $95 \%)$.

Solubility in methanol was the first evidence of successful transformation of the $\mathbf{B r}$ - into $\mathbf{P}^{+}$-unimers. The NMR spectra of modified unimers accordingly showed a ${ }^{31} \mathrm{P}$ signal of $\mathbf{P}^{+}$groups at around $39 \mathrm{ppm}$ (38.93 for $\mathbf{Q} 27-\mathbf{P}^{+}, 38.44$ for $\mathbf{Q 4 5}-\mathbf{P}^{+}$, 39.99 for $\mathbf{Q} 2457-\mathbf{P}^{+}$), ${ }^{1} \mathrm{H}$ signals of ethyl groups (part of $\mathbf{P}^{+}$) but no signal at $3.4 \mathrm{ppm}$ that is typical of $\mathrm{CH}_{2}-\mathrm{Br}$ groups. Weak ${ }^{1} \mathrm{H}$ signals at $5.93 \mathrm{ppm}$ and 5.55-5.45 ppm were also observed indicating that some side chains contain terminal double bonds formed by dehydrobromination accompanying quaternization of Br-unimers. Complete removal of imperfect molecules from $\mathbf{P}^{+}$-unimers was not successful since they are soluble in alcohols.

TGA analyses of Br-unimers and $\mathbf{P}^{+}$-unimers showed thermal stability up to $205^{\circ} \mathrm{C}$.

Metallo-supramolecular polymers were simply prepared by mixing solutions of a given unimer and zinc(II) or iron(II) perchlorate in the metal ions to a unimer mole ratio of $r=1(r=$ $\left[\mathrm{Mt}^{2+}\right] /[$ unimer] $)$. Br-unimers were assembled in the acetonitrile/chloroform mixed solvent (1/1 by vol.) while $\mathbf{P}^{+}$-unimers were assembled in methanol.

The solubility of the prepared unimers and polymers depends on the substitution of the unimer central block. The unsubstituted unimer $\mathbf{Q}$ is soluble in dichloromethane but poorly soluble in chloroform. Br-unimers are highly soluble in solvents such as THF, $\mathrm{CHCl}_{3}, \mathrm{CH}_{2} \mathrm{Cl}_{2}$, DMSO and the acetonitrile/chloroform mixture, which facilitates their isolation and purification. Unimers with two ionic groups are highly 
a)
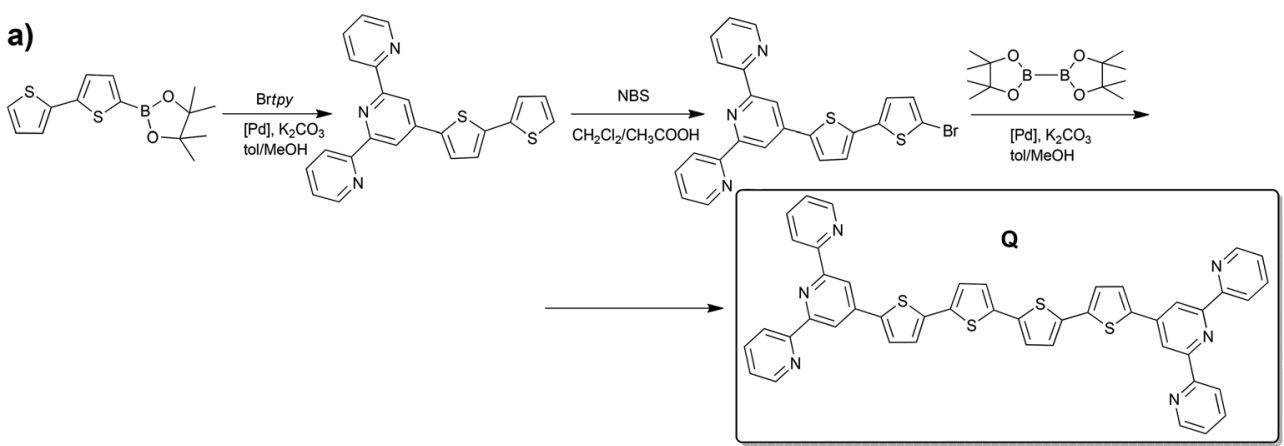

b)

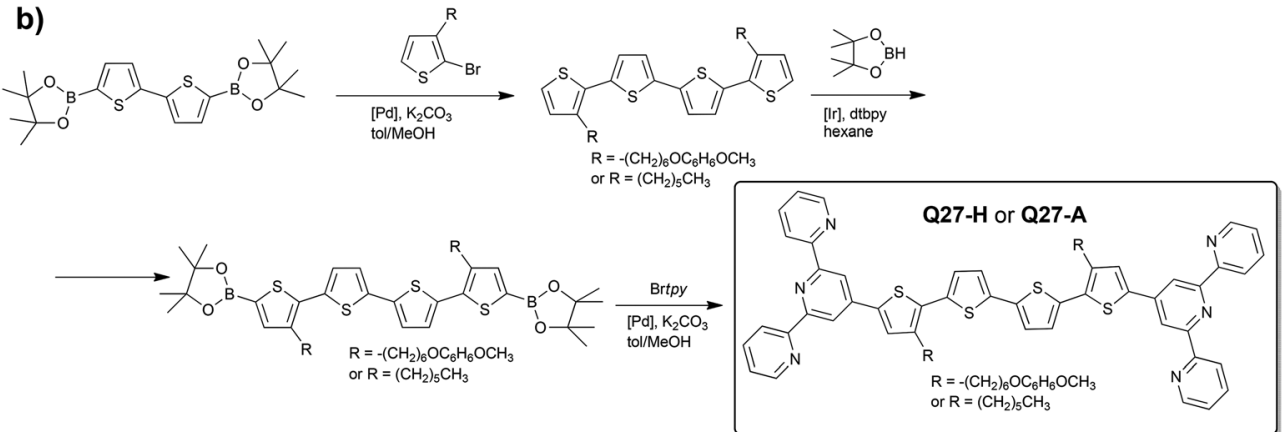

c)

C)
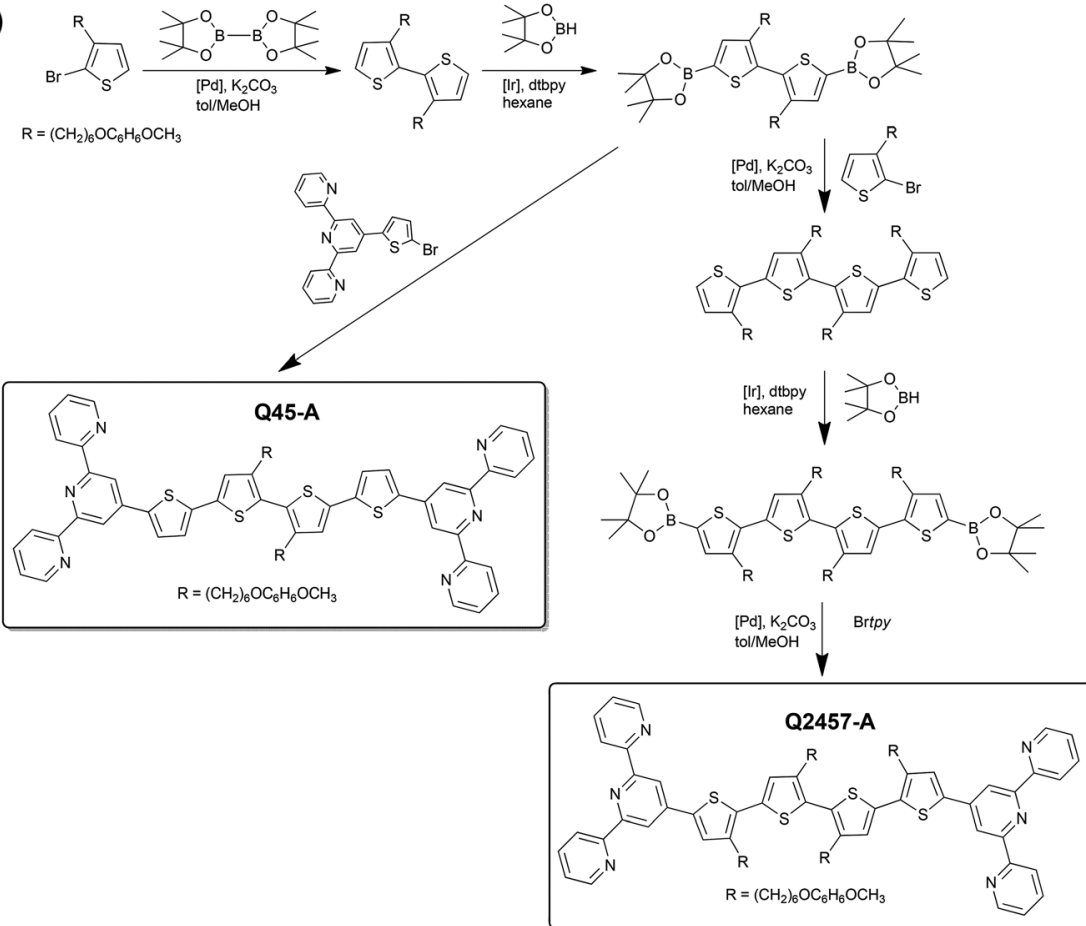

Scheme 1 Synthesis pathways to the reference unimers $\mathrm{Q}$ and Q27-H and A-unimers.

soluble in polar solvents such as methanol, ethanol and DMSO and sparingly soluble in water (complete dissolution to a colloidal solution takes a few weeks). Unimer Q2457- $\mathbf{P}^{+}$carrying four ionic groups is easily soluble in water, which is quite unusual for this type of conjugated structure. Nevertheless, complete dissolution of $\mathbf{Q 2 4 5 7}-\mathbf{P}^{+}$to the molecular level takes time on the day scale as can be seen from the time develop- ment of the UV/vis spectrum of its aqueous solution shown in Fig. S1, ESI. $\dagger$ MSPs show similar solubility to the corresponding unimers.

\section{Vibrational spectra of unimers and polymers}

The IR spectra of unimers show each the bands of stretching modes $\left(\nu_{\mathrm{CC}}, \nu_{\mathrm{CN}}\right)$ of tpy end-groups $\left(1500-1620 \mathrm{~cm}^{-1}\right)$, the 


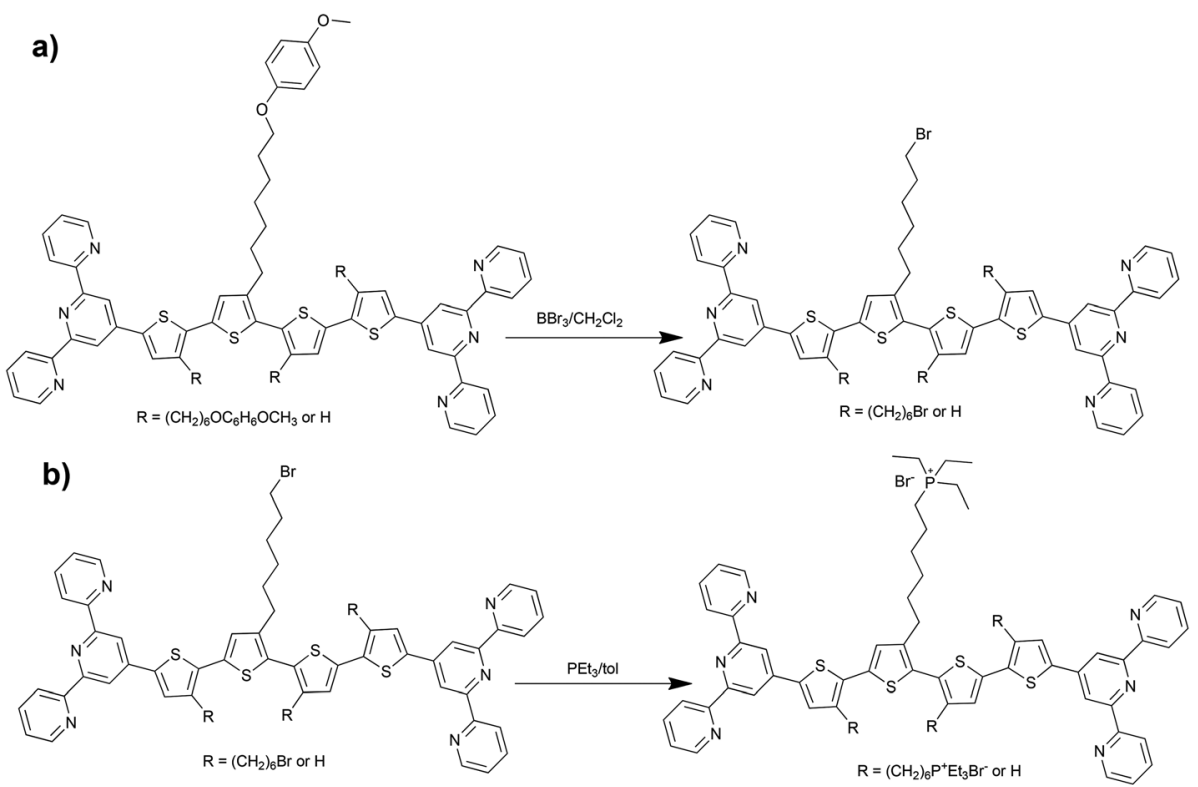

Scheme 2 Transformation of the type A-unimers into type $\mathrm{Br}$ - (a) and type $\mathrm{P}^{+}$-unimers (b).

quaterthiophene central block $\left(1370-1500 \mathrm{~cm}^{-1}\right)$, aromatic $\nu_{\mathrm{CH}}$ modes (3000-3100 $\left.\mathrm{cm}^{-1}\right)$ and the main out-of-plane modes $\left(\rho_{\mathrm{CH}}\right)$ of aromatic moieties $\left(790\right.$ and $\left.658 \mathrm{~cm}^{-1}\right)$ at nearly identical positions (Fig. S2, ESI†). Differences due to different substitutions of the central blocks are mainly seen in the fingerprint region from 850 to $1350 \mathrm{~cm}^{-1}$. The presence of hexyl chains is mainly observable in the $\mathrm{C}-\mathrm{H}$ stretching region (2800-3000 $\left.\mathrm{cm}^{-1}\right)$. The most intensive bands characteristic of vibrations of hexyl groups in the fingerprint region (1466 and $1379 \mathrm{~cm}^{-1}$ ) are overlapped by the ring stretching modes of the quaterthiophene central blocks. Only a small shift of the band maximum from $1459 \mathrm{~cm}^{-1}$ (for Q) to $1466 \mathrm{~cm}^{-1}$ (for $\mathbf{Q} 27-\mathbf{H}$ ) and a new shoulder at $1384 \mathrm{~cm}^{-1}$ for $\mathbf{Q} 27-\mathbf{H}$ are observable. The broad spectral band at $3400 \mathrm{~cm}^{-1}$ observed for all $\mathbf{P}^{+}$-unimers is due to the presence of hydrogen bonded water molecules in these unimers.

The off-resonance Raman spectra of unimers show strong stretching bands of quaterthiophene blocks but weak bands of tpy end-groups. Their spectral patterns reflect differences in the substitution of quaterthiophene blocks (Fig. S3, ESI†). The Raman spectra of Zn-polymers were disturbed by strong fluorescence but spectra of non-fluorescent Fe-polymers were well measurable. The bands characteristic of tpy groups $^{35}$ occur at $1610 \mathrm{~cm}^{-1}\left(\nu_{\mathrm{s}}\right), 1290 \mathrm{~cm}^{-1}\left(\delta_{\mathrm{ip}}\right)$ and $1038 \mathrm{~cm}^{-1}$ (breathing mode) while the bands of quaterthiophene blocks ${ }^{36-38}$ occur in the region $1380-1520 \mathrm{~cm}^{-1}$ (Fig. S4a-S7a, ESI $\dagger$ ). Deconvolution of the latter band using the OMNIC software gave robust results, showing that this band is composed of at least five bands (Fig. S4b-S7b, ESI †) whose intensities depend on the positions of side groups. The band at $1472 \mathrm{~cm}^{-1}$ should also be attributed to transitions in tpy groups. ${ }^{35}$

\section{Optical spectra of unimers and polymers}

The solution UV/vis absorption spectra of unimers (ESI, Fig. S8a †) show: (i) a flat band at 280-284 nm mainly contributed by transitions in tpy end groups, and (ii) a band with the apex at a wavelength $\lambda_{\mathrm{A}}$ from $381 \mathrm{~nm}\left(\mathbf{Q} 2457-\mathbf{P}^{+}\right)$to $441 \mathrm{~nm}(\mathbf{Q})$ belonging to transitions from HOMO that is spread over thiophene rings and central rings of tpy groups. ${ }^{28,33}$ The value of $\lambda_{\mathrm{A}}$ (see Table 1) decreases (i) with increasing distortion of the quaterthiophene central block (see Table 2), and (ii) on going from the non-ionic $(-\mathbf{B r},-\mathbf{H})$ to ionic unimer $\left(-\mathbf{P}^{+}\right)$of the same type. Absorption maxima in the spectra of unimer thin films (ESI, Fig. S8b†) are not in such good correlation with the chain distortion, which reflects the importance of the molecular packing effect or the electronic effect of substituents. An exceptionally high $\lambda_{\mathrm{A}}$ of Q2457-Br thin films (500 $\pm 10 \mathrm{~nm}$ ) was obtained. The fact that Q2457-P $\mathbf{P}^{+}$shows much lower $\lambda_{\mathrm{A}}$ can be ascribed to the bulkiness of $\mathrm{P}^{+} \mathrm{Et}_{3}$ groups and the effect of bromine counterions.

In the spectra of Zn-polymers, the absorption band of transitions involving quaterthiophene blocks is red shifted by about 35-65 nm compared to its position $\lambda_{\mathrm{A}}$ for the unimer in the solution spectra and by about $20-75 \mathrm{~nm}$ in thin films (Table 1). The only but great exception is the spectrum of $\mathbf{P}_{\mathbf{Z n} Q 2457-B r}$ thin films that surprisingly shows a blue shift of $\lambda_{\mathrm{A}}$ of about $-70 \mathrm{~nm}$, which is obviously due to the exceptionally high value of $\lambda_{\mathrm{A}}$ of the unimer Q2457-Br.

The spectra of Fe-polymers contain a new band belonging to transitions in the metal-to-ligand charge transfer (MLCT) complex which is typical of tpy-Fe-tpy linkages ${ }^{35,39}$ (see Table 1 and Fig. S8c and S8d in the ESI $\dagger$ ). In Fe-polymers, this band is significantly contributed by transitions involving neighboring oligothiophene blocks. ${ }^{29}$ 
Table 1 UV/vis and luminescence spectral characteristics of the prepared unimers and polymers; solvent: methanol for ionic unimers and polymers (suffix $-\mathrm{P}^{+}$); acetonitrile/chloroform (1/1 by vol.) for all the other unimers and polymers. $\lambda_{\mathrm{A}}-$ apex of absorbance maxima; $\lambda_{\mathrm{F}}-$ apex of emission maxima; $\nu$ - Stokes shift; $\lambda_{\text {MLCT }}$ - apex of the MLCT band; $\Phi$ - absolute luminescence quantum yield

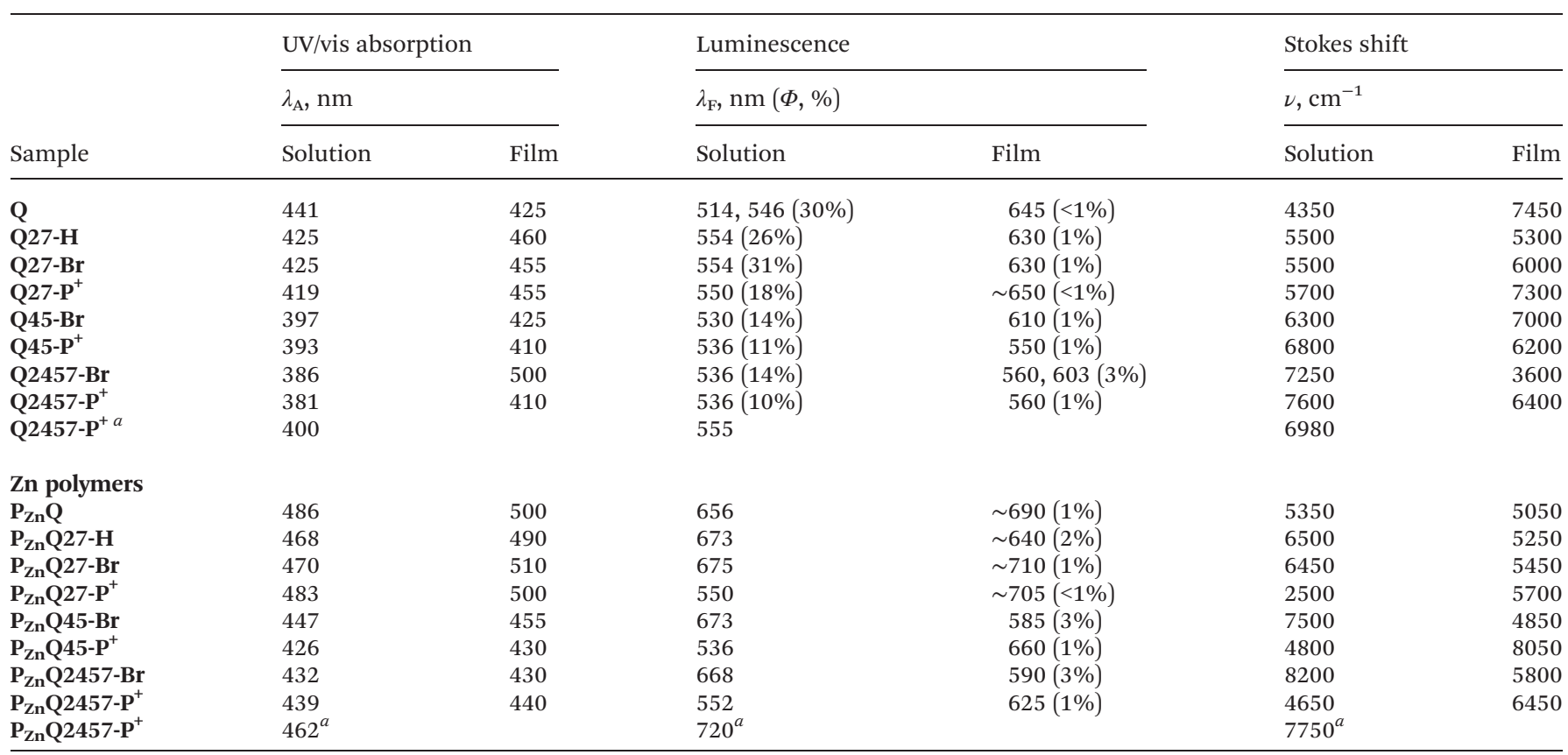

Fe polymers

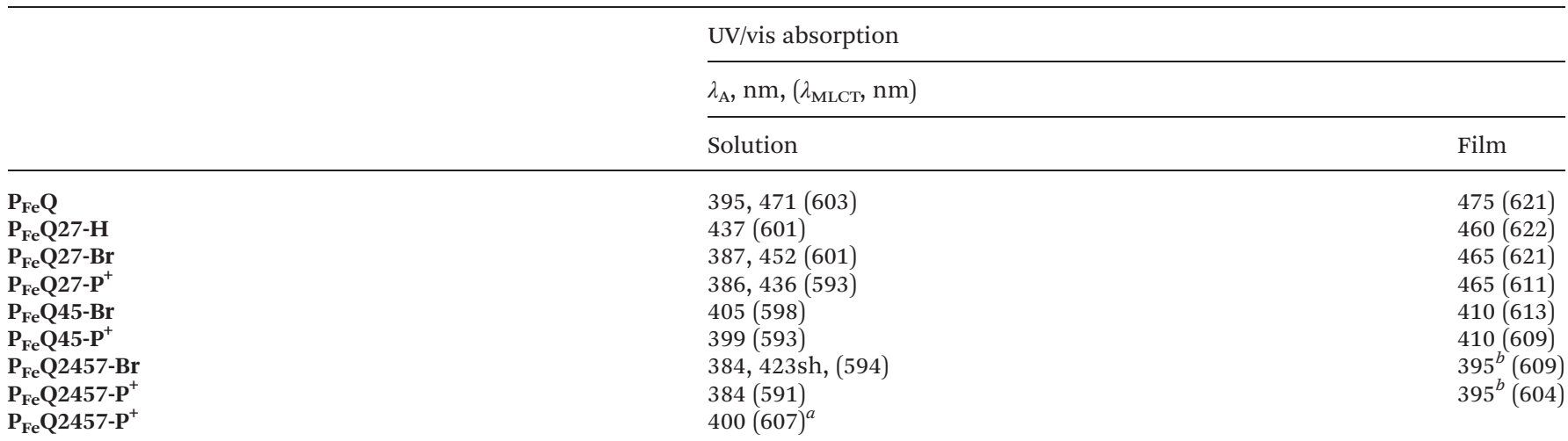

${ }^{a}$ Data from aqueous solution. ${ }^{b}$ Shoulder.

Table 2 Calculated geometry of the unimers; $\delta_{\mathrm{BC}} \cdots \delta_{\mathrm{DD}^{\prime}}$ are dihedral angles between the planes of neighbouring main-chain rings given in subscript (for ring labels see Chart 1)

\begin{tabular}{|c|c|c|c|c|c|c|}
\hline & \multicolumn{3}{|c|}{ Ground state } & \multicolumn{3}{|c|}{ Excited state } \\
\hline & $\delta_{\mathrm{BC}}$ & $\delta_{\mathrm{CD}}$ & $\delta_{\mathrm{DD}^{\prime}}$ & $\delta_{\mathrm{BC}}$ & $\delta_{\mathrm{CD}}$ & $\delta_{\mathrm{DD}^{\prime}}$ \\
\hline Q & 15.8 & 12.5 & 0.7 & 0.0 & 0.0 & 0.0 \\
\hline Q27-H & 17.3 & 28.6 & 1.0 & 0.0 & 0.0 & 0.0 \\
\hline Q27-Br & 13.9 & 22.8 & 1.0 & 0.5 & 3.2 & 1.3 \\
\hline 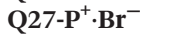 & 17.3 & 32.4 & 16.3 & $a$ & $a$ & \\
\hline Q45-Br & 14.6 & 18.5 & 58.9 & 1.4 & 3.1 & 23.7 \\
\hline $\mathrm{Q} 45-\mathrm{P}^{+} \cdot \mathrm{Br}^{-}$ & 18.0 & 15.4 & 63.5 & $a$ & $a$ & \\
\hline Q2457-Br & 19.6 & 40.8 & 97.5 & $a$ & $a$ & $a$ \\
\hline Q2457- $-\mathrm{P}^{+} \cdot \mathrm{Br}^{-}$ & 15.8 & 27.4 & 124.4 & $a$ & $a$ & $a$ \\
\hline
\end{tabular}

${ }^{a}$ Values are not available for the first 720 hours.
Luminescence spectra of unimers in solutions (ESI, Fig. S9a $\dagger)$ show higher similarity than their UV/vis spectra $\left(\lambda_{\mathrm{F}}\right.$ around $550 \mathrm{~nm}$; lowered values of about $535 \mathrm{~nm}$ are actually given by different band shapes). This is obviously due to the fast transition of excited unimer molecules to nearly coplanar conformations with quinoidal rings, from which the light emission takes place. ${ }^{36}$ Minor differences are nevertheless seen: unimers with less distorted chains (Q, Q27-H, Q27-Br and $\mathbf{Q} 27-\mathbf{P}^{+}$) show a better resolved vibrational structure than unimers with more distorted chains (Q45-Br, Q45-P' $\mathbf{P}^{+}, \mathbf{Q} 2457-\mathrm{Br}$

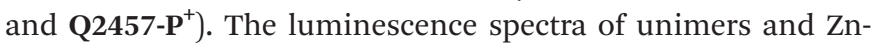
polymer thin films are shown in ESI, Fig. S9b-d† and the band wavelengths are summarized in Table 1 , and the luminescence lifetimes are presented in ESI, Table S1. $\dagger$ Fe-polymers do not show luminescence. ${ }^{28,29,36}$ 


\section{Assembly of unimers to metallo-supramolecular polymers in solutions}

The assembly in solutions was monitored by UV/vis and luminescence spectroscopy, viscometry and size exclusion chromatography (SEC). A chloroform/acetonitrile mixed solvent (1/1 by volume) was used for Br-unimers while methanol and water were used for $\mathbf{P}^{+}$-unimers. For spectroscopic studies, a set of solutions of a constant unimer concentration $\left(2 \times 10^{-5} \mathrm{M}\right)$ and a stepwise increasing metal ions to unimer mole ratio ( $r$ from 0 to 3 ) was prepared for each $\mathrm{Mt}^{2+} /$ unimer system and solutions were allowed to equilibrate for 24 hours before monitoring the spectra. The SEC and viscometric measurements were done with solutions of the concentration of $5 \times 10^{-4} \mathrm{M}$.

Spectral changes accompanying the assembly of unimers with $\mathrm{Mt}^{2+}$ ions showed three stages differing in the development trend, similarly to the related systems studied recently. ${ }^{21,25,28,29,40}$ The UV/vis spectra obtained for systems of composition ratios $r$ from 0 to $c a$. 0.5 (the first stage of assembly) showed up to three isosbestic points (see examples in Fig. $1 \mathrm{a}$ and $2 \mathrm{a}$ and a complete set of the spectra in ESI, Fig. S10 and S11 $\dagger$ ), which indicates the transformation of the unimer species into another well-defined species. Regarding the stoichiometry, the new species should be a dimer species unimer-Mt ${ }^{2+}$-unimer.

The spectra obtained for systems with ratios $r$ from $c a$. 0.6 to 1 also show isosbestic points but at different wavelengths (Fig. $1 \mathrm{~b}$ and $2 \mathrm{~b}$ ). This indicates that the systems entered the second stage of assembly in which longer polymer chains are formed. As can be seen from ESI, Fig. S10 and S11, $\dagger$ the absorption bands characteristic of free unimers and dimers disappear while the band of enchained unimer units fully develops in the case of systems with non-ionic Br-unimers. These systems then enter the third stage of assembly $(r>1)$, where spectral changes are quite low and can be attributed to the end-capping of polymer chains with the metal ions and partial depolymerization of the polymer chains to the shorter
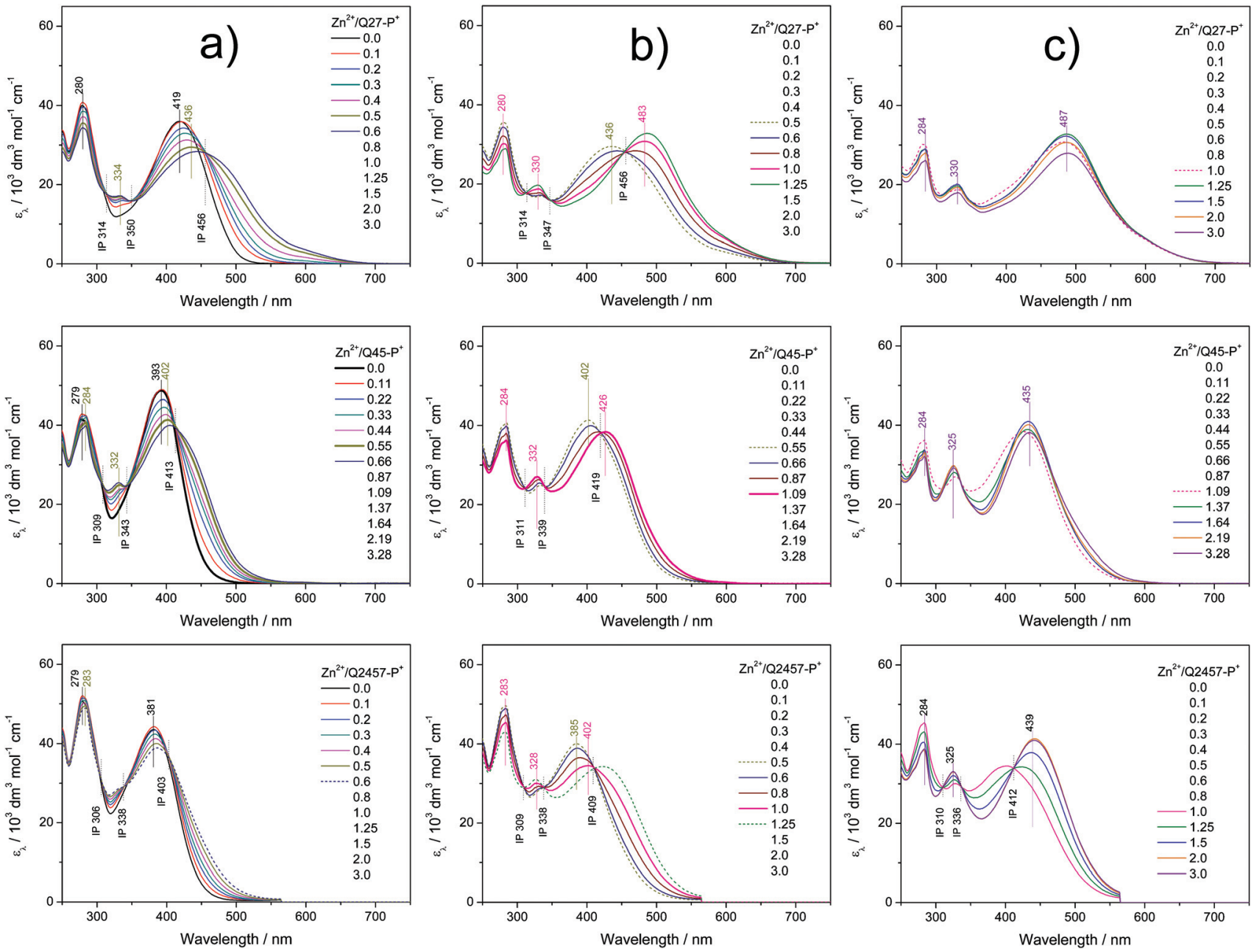

Fig. 1 Changes in UV/vis spectra accompanying the titration of ionic unimers with $\mathrm{Zn}^{2+}$ ions. Initial unimer concentration $2 \times 10^{-5} \mathrm{M}$ in methanol, room temperature. Column (a) shows the first stage of assembly, column (b) shows the second stage and column (c) shows the third stage; see the text. 

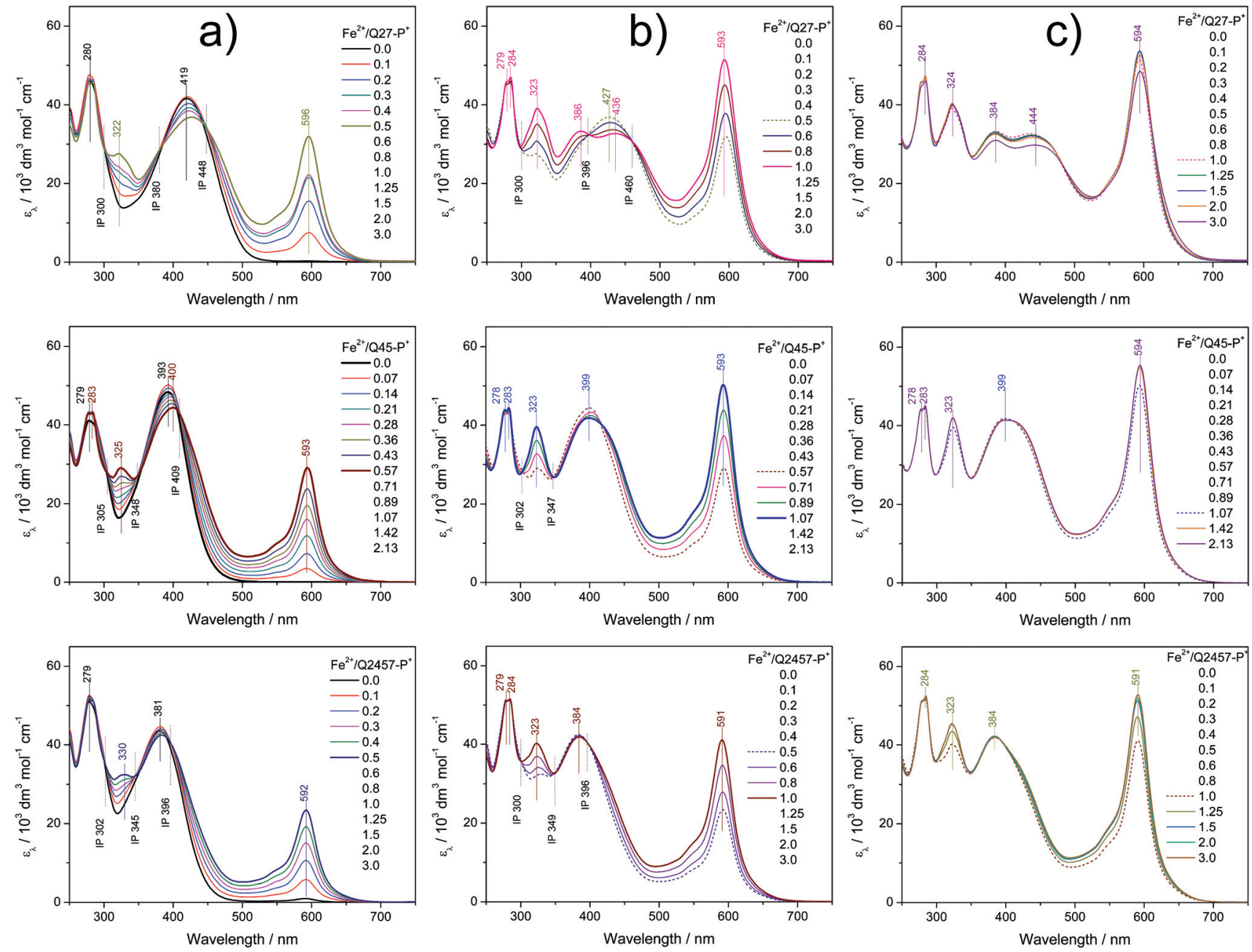

Fig. 2 Changes in UV/vis spectra accompanying the titration of ionic unimers with $\mathrm{Fe}^{2+}$ ions. Initial unimer concentration $2 \times 10^{-5} \mathrm{M}$ in methanol, room temperature. Column (a) shows the first stage of assembly, column (b) shows the second stage and column (c) shows the third stage; see the text.

also end-capped ones (Fig. 1c and 2c). The reaction of $(t p y)_{2} \mathrm{Zn}^{2+}$ species with $\mathrm{Zn}^{2+}$ ions giving two (tpy) $\mathrm{Zn}^{2+}$ species has been reported for mono- as well as bis(tpy) species. ${ }^{18,29,41,42}$ The reaction of $(t p y)_{2} \mathrm{Fe}^{2+}$ species with $\mathrm{Fe}^{2+}$ ions giving two (tpy) $\mathrm{Fe}^{2+}$ species was reported only for metallosupramolecular polymers. ${ }^{18,29,43}$

The spectral changes in the second stage of assembly of ionic $\mathbf{P}^{+}$-unimers are less progressive than those in the case of Br-unimers or even incomplete, which indicates lowered thermodynamic stability (i.e., stability constants) of ionic polymers in methanol. The lowered stability of ionic Fe-polymers is also seen from the changes in the position and intensity of the MLCT band (at around $595 \mathrm{~nm}$ ) that is not fully developed at the ratio $r \cong 1$ (Fig. $2 \mathrm{~b}$ ). The UV/vis spectral patterns indicate that the ionic polymers acquire their maximum length at the ratios $r$ of about 1.5 or higher in methanol solutions.

The changes in luminescence spectra accompanying the assembly of ionic unimers with $\mathrm{Zn}^{2+}$ ions are shown in Fig. 3 .
The complexation is manifested by the disappearance of the unimer emission band and the creation of a new band red shifted by about $130 \mathrm{~nm}$. Unlike the case of shorter ionic polymers derived from bis(tpy) mono- and bithiophenes, ${ }^{29}$ the new emission band is much less intense than the band of free unimers. A similar luminescence attenuation is also exhibited by systems with non-ionic polymers. This shows that the prolongation of the unimer central oligothiophene block increases the efficiency of non-radiative paths of the decay of excited states in Zn-polymers.

Unlike the systems with $\mathrm{Zn}^{2+}$ ions, those with $\mathrm{Fe}^{2+}$ ions show a monotonous luminescence quenching with increasing ratios $r$ up to $c a$. 0.6, at which the luminescence disappears (for example see ESI, Fig. S12 $\dagger$ ). This behaviour, which is exhibited by other systems with bis(tpy) $\mathrm{Fe}^{2+}$ species, is attributed to the fact that the lowest excited state of bis(tpy) $\mathrm{Fe}^{2+}$ species, the $d-d$ triplet state, is close to the ground state. ${ }^{44}$ As the $\mathrm{d}-\mathrm{d}$ triplet state easily depletes higher excited states and potential phosphorescence from the $d-d$ state is spin forbid- 

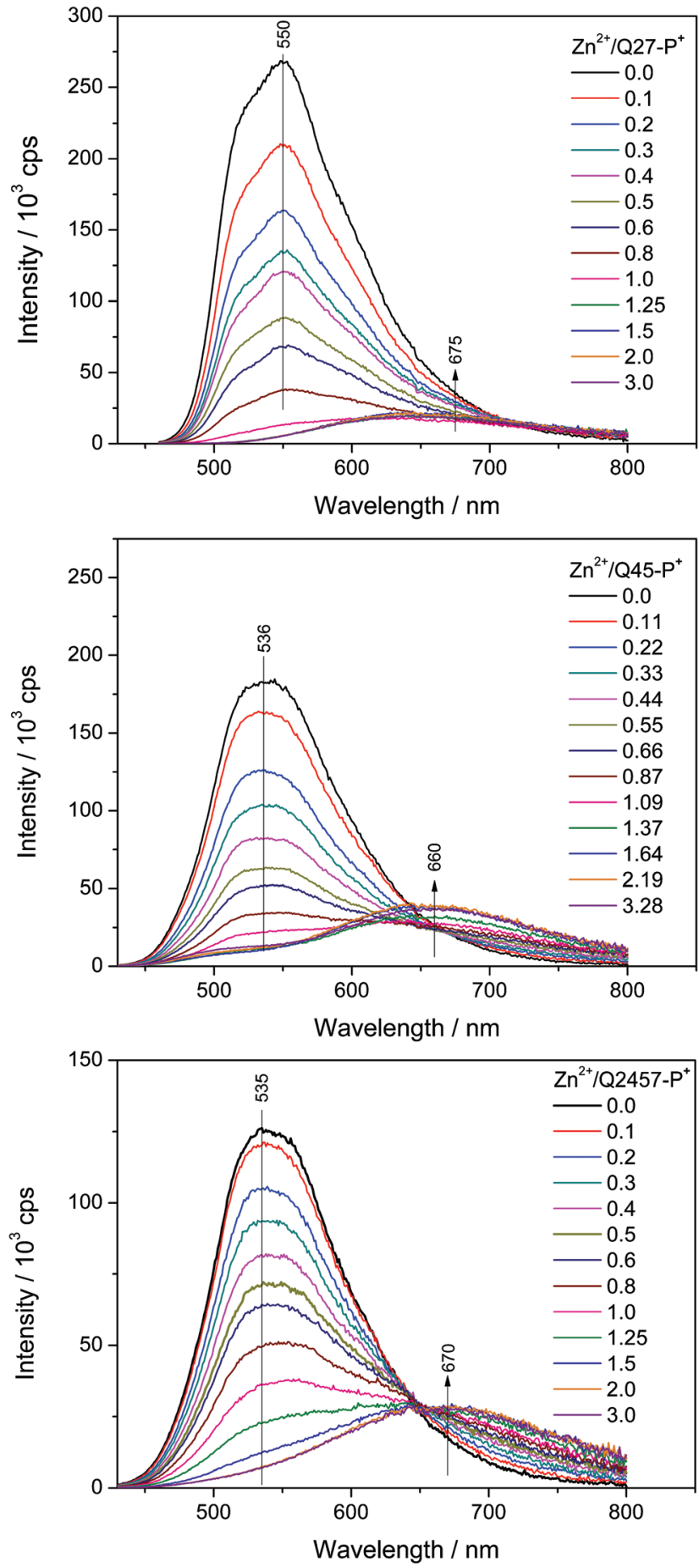

Fig. 3 Changes in photoluminescence spectra accompanying the titration of ionic unimers with $\mathrm{Zn}^{2+}$ ions. Initial unimer concentration $2 \times 10^{-5} \mathrm{M}$ in methanol, room temperature.

den, its decay by non-radiative transitions is unambiguously preferred in accord with the energy gap law. ${ }^{8,45}$

The molar mass distribution of Br-polymers in $\mathrm{CHCl}_{3} /$ $\mathrm{CH}_{3} \mathrm{CN}(1: 1)$ solutions was examined using an SEC system equipped with a diode-array UV/vis detector (DAD). (Analysis of ionic polymers failed owing to the strong adsorption of their chains inside SEC columns.) Mixed solutions of a $\mathbf{B r}-$ unimer (0.5 mM) and $\mathrm{Zn}^{2+}$ or $\mathrm{Fe}^{2+}$ ions ( $r$ from 0 to 2.0) equilibrated for one day were injected into the SEC system. The SEC records of systems with $\mathrm{Zn}^{2+}$ ions showed nothing but the peak of free unimers, which proves rapid dissociation of the Zn-polymer chains upon multifold dilution of their solution inside SEC columns. In contrast, the systems with $\mathrm{Fe}^{2+}$ ions provided SEC records typical of covalent polymers (Fig. 4 and ESI, S13†), which demonstrates very slow constitutional dynamics of Fe-polymers in the used solvent. Similar results were recently obtained for MSPs of shorter bis(tpy)thiophenes. ${ }^{29}$

Well resolved SEC records were obtained only for systems with a composition ratio $r<1$ (Fig. 4). Systems with $r \geq 1$ gave poorly resolved SEC records, in which the area under the elution peak decreased with increasing value of $r$. This indicates retention of longer chains in SEC columns. The detained polymer chains, obviously end-capped with $\mathrm{Fe}^{2+}$ ions, had to be additionally washed out of the columns with 2,2'-bipyridine. The UV/vis spectral pattern of SEC fractions showed a perfect development with the elution time $\left(t_{\mathrm{el}}\right)$ : a pattern typical of long polymer chains was observed for the first eluted SEC fractions while that typical of the dimers for the last fraction (Fig. 5a and ESI, Fig. S14a†). Differences are also seen when comparing the spectra of fractions of dimers formed in systems of different compositions (Fig. 5b and ESI, Fig. S14b $\dagger$ ). These differences can be attributed to the endcapping of their molecules with $\mathrm{Fe}^{2+}$ ions. However, these differences are substantially smaller than those observed for the Fe-polymers formed from unimers with mono- and bithiophene central blocks. ${ }^{29}$

The presence of higher fractions in solutions containing a stoichiometric lack of $\mathrm{Fe}^{2+}$ ions $(r=0.2$ and 0.5$)$ can be explained by the transiently locally increased concentration of the ions and unimers during mixing of their solutions. The formation of polymer chains is most likely a kinetically con-

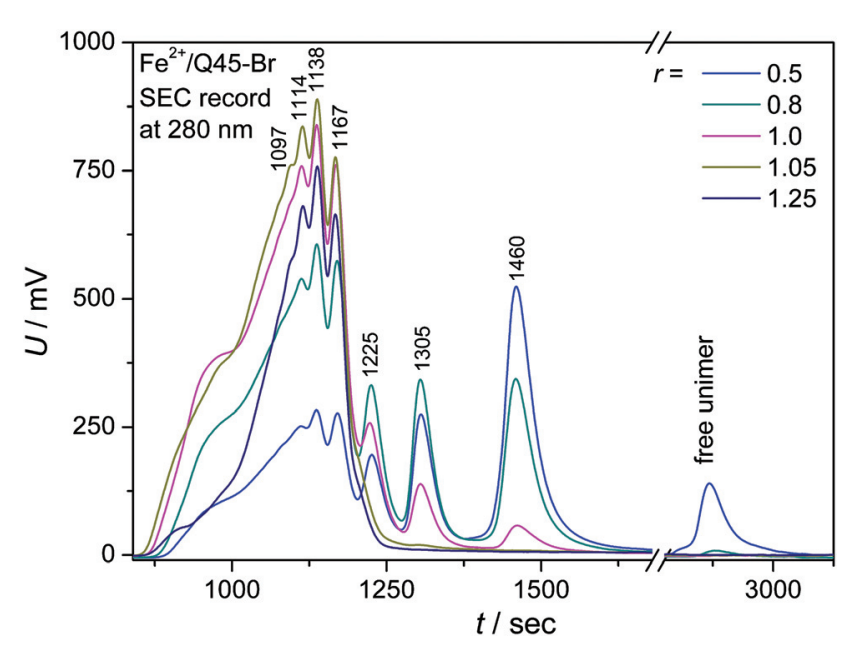

Fig. 4 The SEC records of the $\mathrm{Fe}^{2+} / \mathrm{Q} 45-\mathrm{Br}$ systems of different compositions. 

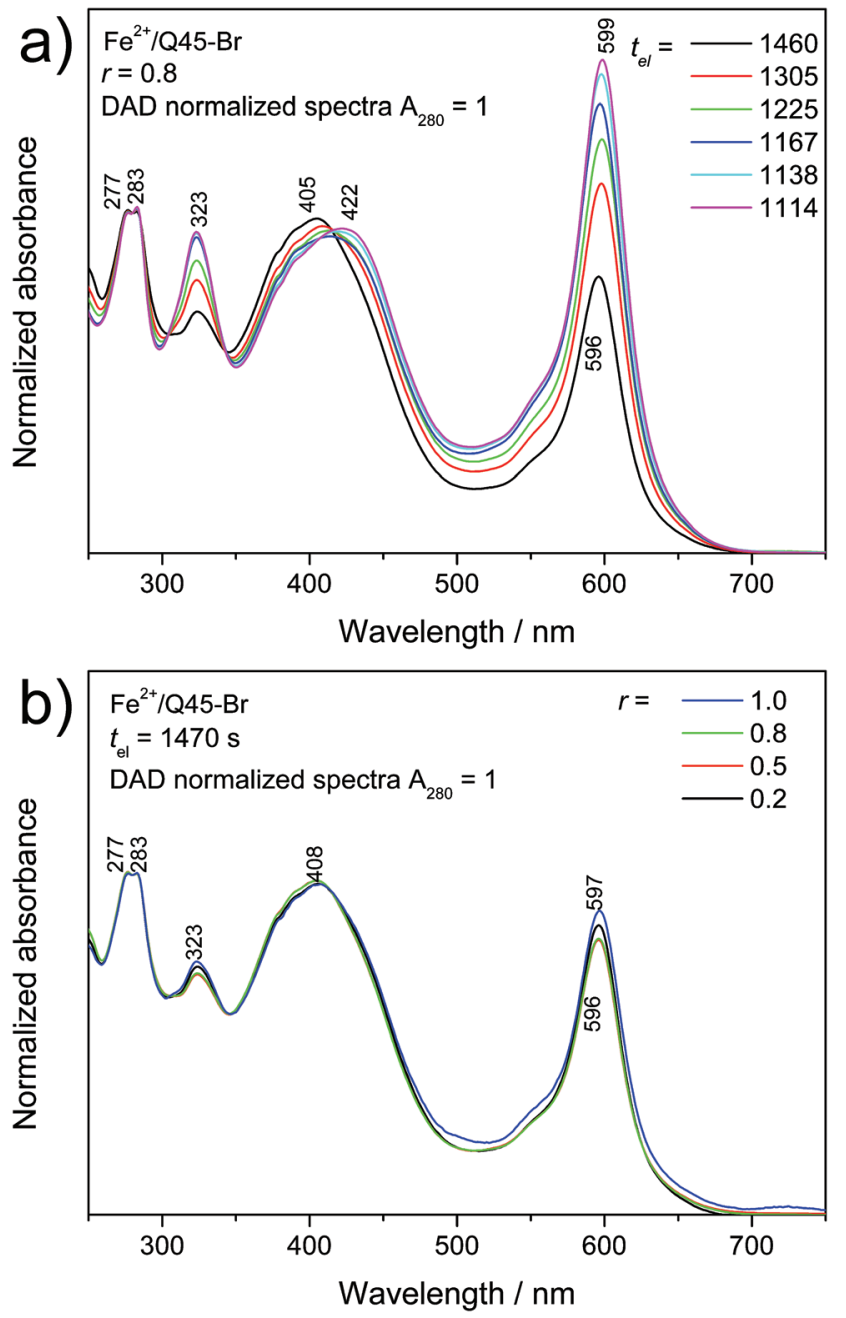

Fig. 5 The UV/vis DAD spectra of SEC fractions of the $\mathrm{Fe}^{2+} / \mathrm{Q} 45-\mathrm{Br}$ system $(r=0.8)$ eluted at different elution times $t_{\mathrm{el}}(\mathrm{a})$ and comparison of the spectra of the last fraction (dimers; $t_{\mathrm{el}}=1470 \mathrm{~s}$ ) of systems of composition $r$ from 0.2 to 1.0 (b).

trolled process which, on mixing twenty five times more concentrated solutions ( $0.5 \mathrm{mM}$ instead of $0.02 \mathrm{mM}$ ), shall be $c a$. 625 times accelerated. Thus it can give rise to a significant number of longer chains that do not dissociate during the SEC analysis thanks to their slow constitutional dynamics. Thus the degree of polymerization, $X$, of Fe-polymer chains in solution could be estimated. If the peak eluted at $t_{\mathrm{el}}=1460 \mathrm{~s}$ (see Fig. 4) is ascribed to dimers, the peak with $t_{\mathrm{el}}=1305 \mathrm{~s}$ to trimers, and so on, one can still resolve the peak of heptamers at $t_{\mathrm{el}}=1114 \mathrm{~s}$. Calculations based on this peak assignment provide the weight-average degree of polymerization equal to ca. 7 for Fe-polymer in the solution with $r \cong 1$ (Table 3). In addition, it is seen from Fig. 4 that the stoichiometric excess of $\mathrm{Fe}^{2+}$ ions in solution results in the formation of shorter chains. The latter is supported by the results of viscometric measurements, which also indicate shortening of the polymer chains in the presence of excess $\mathrm{Fe}^{2+}$ ions (ESI, Fig. S15†).
Table 3 Number-average $\left(X_{n}\right)$ and weight-average $\left(X_{\mathrm{w}}\right)$ degrees of polymerization and dispersity index $(\Theta)$ of $\mathrm{P}_{\mathrm{Fe}} \mathrm{Q} 45-\mathrm{Br}$ in solution calculated from SEC records

\begin{tabular}{llll}
\hline$r$ & $X_{n}$ & $X_{\mathrm{W}}$ & $D$ \\
\hline 0.2 & 3.07 & 4.23 & 1.36 \\
0.5 & 3.24 & 4.77 & 1.47 \\
0.8 & 4.43 & 6.02 & 1.36 \\
1.0 & 6.13 & 7.23 & 1.18 \\
1.05 & 6.79 & 7.62 & 1.12 \\
1.25 & 6.26 & 6.84 & 1.09
\end{tabular}

\section{Assembly of Q2457- $\mathrm{P}^{+}$in water}

The water-soluble unimer Q2457- $\mathbf{P}^{+}$has been assembled with metal ions also in aqueous solutions. Since molecular dissolution of this unimer in water takes a long time a month-old solution of Q2457- $\mathbf{P}^{+}$was used in these experiments. As can be seen from Fig. 6, the optical spectral changes accompanying the assembly in water substantially differ from those observed for assembly in methanol.

(i) The absorption maxima of Q2457-P $\mathbf{P}^{+}\left(\lambda_{\mathrm{A}}=400 \mathrm{~nm}\right)$ and its Zn-polymer $\left(r=2, \lambda_{\mathrm{A}}=462 \mathrm{~nm}\right)$ as well as the luminescence maximum of the unimer $\left(\lambda_{\mathrm{F}}=555 \mathrm{~nm}\right)$ are red shifted by about $c a .20 \mathrm{~nm}$ compared to their positions in methanol solutions, which indicates that the free as well as enchained unimer species acquire more planar conformations in water than in methanol. This can be attributed to the substantial increase in the solvent permittivity, which, in accord with the Coulomb law, reduces repulsive ionic interactions among neighbouring $\mathrm{P}^{+} \mathrm{Et}_{3}$ groups as well as their attractive interactions with counterions.

(ii) The luminescence emission band observed for $\mathrm{Zn}$ polymer $\left(\lambda_{\mathrm{F}}=720 \mathrm{~nm}\right)$ is enormously red shifted (about $168 \mathrm{~nm}$ ) compared to the band for methanol solution. The Stokes shift for $\mathbf{P}_{\mathbf{Z n}} \mathbf{Q}$ 2457- $\mathbf{P}^{+}$in water $\left(7750 \mathrm{~cm}^{-1}\right)$ is much higher than the shift in methanol $\left(4650 \mathrm{~cm}^{-1}\right.$, Table 1), which proves the much higher extent of conformational relaxation of excited states in aqueous compared to methanol solutions.

(iii) The UV/vis spectra for assembly of Q2457- $\mathbf{P}^{+}$with $\mathrm{Zn}^{2+}$ ions show a single set of isosbestic points and a fluent course of changes up to $r=2$. Luminescence spectra indicate the presence of free unimers in solution with $r$ equal to at least 1.5. These features consistently indicate a lowered stability and increased constitutional dynamics of $\mathbf{P}_{\mathbf{Z n}} \mathbf{Q} \mathbf{2 4 5 7}-\mathbf{P}^{+}$in aqueous solutions.

(iv) Surprisingly, in accord with the last mentioned observations, the UV/vis spectra for assembly of Q2457-P $\mathbf{P}^{+}$with $\mathrm{Fe}^{2+}$ ions show small changes and a weak MLCT band and the luminescence spectra show emission even at the composition ratio $r=3$. It should be stressed here that no new emission band occurs; only reluctant luminescence quenching with increasing $r$ is observed. The observed spectral changes indicate that the chains of a highly ionic Fe-polymer are, in aqueous solution, less stable than the chains of its $\mathrm{Zn}$-counterpart. This observation represents a flip in the stability of 

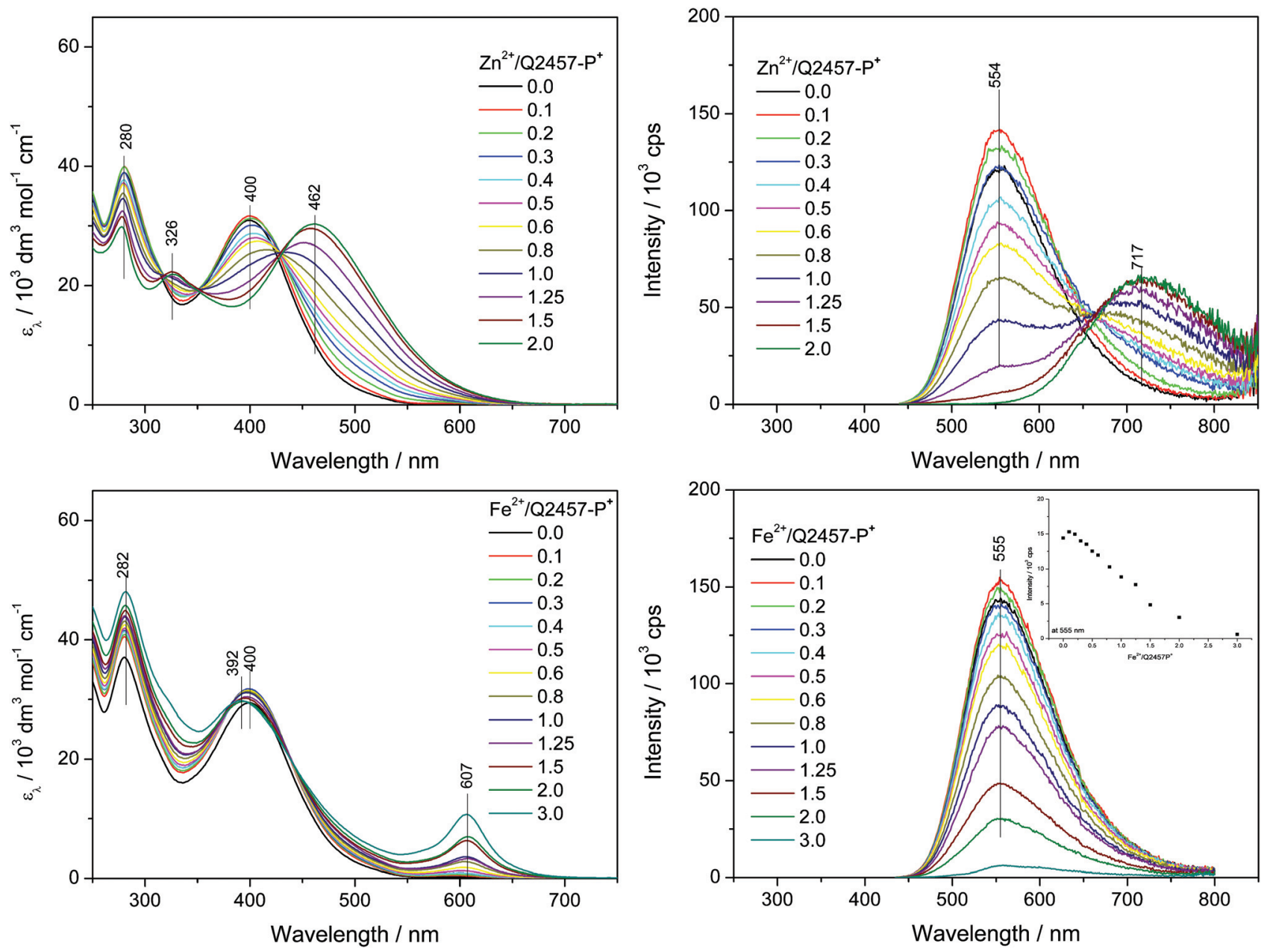

Fig. 6 Changes in UV/vis (left column) and photoluminescence (right column) spectra accompanying the titration of ionic unimers with $\mathrm{Zn}^{2+}$ or $\mathrm{Fe}^{2+}$ ions. Initial unimer concentration $2 \times 10^{-5} \mathrm{M}$ in water, room temperature.

Fe- and Zn-polymers derived from bis(tpy)quaterthiophenes compared to perhaps all the data reported so far. ${ }^{41,46-49}$ The reduced stability of the ionic Fe-polymer in water is obviously associated with the inhibition of the MLCT process by water. The solvent dependence of the MLCT is well known. ${ }^{50,51}$

\section{Conclusions}

The synthesis strategy developed here enables preparation of bis(tpy)quaterthiophenes with two or four side groups symmetrically distributed along the quaterthiophene central block. The modification of side groups enabled preparation of ionic unimers that are soluble in green solvents such as alcohols or even in water.

Optical spectral patterns of dissolved unimers and the corresponding polymers depend primarily on the distribution of side groups along the quaterthiophene central block and only secondarily on the nature of side-chain-capping groups. The effect of the latter is more apparent in the solid state spectra since the capping groups significantly influence molecular packing.

During the assembly of unimers with metal ions the development of UV/vis spectra with increasing ratio $r$ conclusively indicates that the $\mathbf{P}^{+}$-unimers assemble with metal ions less readily than the Br-unimers. Besides, in water, Q2457- $\mathbf{P}^{+}$ assembles with $\mathrm{Zn}^{2+}$ ions considerably less progressively (with rising $r$ ) than in methanol and, with $\mathrm{Fe}^{2+}$ ions, still much less readily, showing only a very weak MLCT band but significant luminescence of the free unimer even at the ratio $r=3$. The solvation effect is thus obvious. A red shift of the luminescence band of $\mathbf{P}_{\mathbf{Z n}} \mathbf{Q} 2457-\mathbf{P}^{+}$by about $c a .170 \mathrm{~nm}$ on going from methanol to aqueous solution is observed. Such a big shift indicates much higher conformational freedom of $\mathbf{P}_{\mathbf{Z n}} \mathbf{Q}^{2457-\mathbf{P}^{+}}$chains in aqueous compared to methanol solutions.

The SEC study of the non-ionic polymers proved that the constitutional dynamics of Zn-polymers is fast and that of Fepolymers is very slow in the chloroform/acetonitrile mixed solvent, which is in accord with observations of other authors 
on related systems. However, the results obtained here on assembly of the ionic unimers in aqueous solutions anticipate faster constitutional dynamics of Fe-polymers compared to Znpolymers.

\section{Experimental section}

\section{Materials}

2,2'-Bithiophene-5-boronic acid pinacol ester, 2,2'-bithiophene$5,5^{\prime}$-diboronic acid bis(pinacol) ester, thiophene-2-boronic acid pinacol ester, 3,3"'-dihexyl-2,2':5',2":5",2"'-quaterthiophene, bis(pinacolato)diboron $\left(\mathrm{B}_{2} \mathrm{pin}_{2}\right)$, 4,4,5,5-tetramethyl1,3,2-dioxaborolane (HBpin), 4,4'-di-tert-butyl-2,2'-dipyridyl (dtbpy), bis(1,5-cyclooctadiene)di- $\mu$-methoxydiiridium(I) $\left([\operatorname{Ir}(\mathrm{OMe})(\mathrm{COD})]_{2}\right)$, boron tribromide $\left(\mathrm{BBr}_{3}\right)$, triethylphosphine $\left(\mathrm{PEt}_{3}, 1.0 \mathrm{M}\right.$ in THF), $N$-bromosuccinimide (NBS), [1,3-bis(2,6diisopropylphenyl)imidazol-2-ylidene](3-chloropyridyl)palladium(II) dichloride (PEPPSI-IPr), zinc perchlorate hexahydrate, iron(II) perchlorate hydrate and tetrabutylammonium hexafluorophosphate (all Aldrich), $\mathrm{K}_{2} \mathrm{CO}_{3}, \mathrm{MgSO}_{4}$, acetic acid (Lachner) and $4^{\prime}$-bromo-2,2':6'2"-terpyridine (TCI) were used as received. Hexane (Lachner) was stored over a molecular sieve, tetrahydrofuran (Aldrich) was distilled from $\mathrm{LiAlH}_{4}$ before use, toluene (Lachner) was distilled from sodium/benzophenone before use, methanol (Aldrich) was bubbled with argon before use, and diethylether, dichloromethane, chloroform (Lachner) and acetonitrile (ACN) were used as obtained.

\section{Measurements}

${ }^{1} \mathrm{H}$ and ${ }^{13} \mathrm{C}$ NMR spectra were recorded on a Varian ${ }^{\text {UNITY INOVA }}$ 400 or a Varian SYSTEM 300 instrument in $d_{8}$-THF, $d_{2}-\mathrm{CD}_{2} \mathrm{Cl}_{2}$, $d$ - $\mathrm{CDCl}_{3}, d_{6}$-DMSO or $d_{4}-\mathrm{CD}_{3} \mathrm{OD}$ and referenced to the solvent signal: $7.25 \mathrm{ppm}\left(d-\mathrm{CDCl}_{3}\right), 5.32 \mathrm{ppm}\left(d_{2}-\mathrm{CD}_{2} \mathrm{Cl}_{2}\right), 3.58 \mathrm{ppm}$ ( $d_{8}$-THF), $2.50 \mathrm{ppm}\left(d_{6}\right.$-DMSO) or $3.31 \mathrm{ppm}\left(d_{4}-\mathrm{CD}_{3} \mathrm{OD}\right)$ for ${ }^{1} \mathrm{H}$ and $77.0 \mathrm{ppm}\left(d-\mathrm{CDCl}_{3}\right), 53.84 \mathrm{ppm}\left(d_{2}-\mathrm{CD}_{2} \mathrm{Cl}_{2}\right), 67.57 \mathrm{ppm}$ $\left(d_{8}\right.$-THF) or $49.15 \mathrm{ppm}\left(d_{4}-\mathrm{CD}_{3} \mathrm{OD}\right)$ for ${ }^{13} \mathrm{C}$ spectra. Coupling constants, $J$ (in $\mathrm{Hz}$ ), were obtained by the first-order analysis. Infrared spectra were recorded on a Thermo Nicolet 7600 FTIR spectrometer equipped with a Spectra Tech InspectIR Plus microscopic accessory using KBr-diluted samples and the diffuse reflectance technique (DRIFT) (128 or more scans at a resolution of $4 \mathrm{~cm}^{-1}$ ). Raman spectra of solid samples were recorded on a DXR Raman microscope (Thermo Scientific) using excitations across the whole visible region $\left(\lambda_{\text {ex }}=445\right.$, 532,633 and $780 \mathrm{~nm}$ ) and the usual laser power at the sample of $0.1-0.4 \mathrm{~mW}$. UV/vis spectra were recorded on a Shimadzu UV-2401PC instrument or a SPECORD instrument in methanol or $\mathrm{CHCl}_{3} / \mathrm{ACN}(1 / 1, \mathrm{v} / \mathrm{v})$; solid samples were coated on the surface of a quartz cuvette. Photoluminescence spectra were recorded on a Fluorolog 3-22 Jobin Yvon Spex instrument, using a four-window quartz cuvette $(1 \mathrm{~cm})$ for solutions and using quartz glass for films. The emission spectra were recorded with the excitation wavelength, $\lambda_{\mathrm{ex}}$, matching the absorption maximum of the measured compound. Quantum yields, $\lambda_{\mathrm{F}}$, of photoluminescence were measured using the integration sphere Quanta- $\varphi$ F-3029. Fluorescence decay was monitored with a FluoroHub single photon counting controller on a Fluorolog 3-22 Jobin Yvon Spex instrument using excitation at $\lambda_{\mathrm{ex}}=378 \mathrm{~nm}$ for solutions and $\lambda_{\mathrm{ex}}=472 \mathrm{~nm}$ for films. Viscometric measurements were performed on a Microviscometer Lovis $2000 \mathrm{M} / \mathrm{Me}$ (Anton Paar). SEC records were obtained using a Spectra Physics Analytical HPLC pump P1000 with two SEC columns: Polymer Labs (Bristol, USA) Mixed-D and Mixed-E. The system was equipped with a Thermo UV6000 DAD detector. $0.05 \mathrm{M}$ tetrabutylammonium hexafluorophosphate in $\mathrm{CHCl}_{3} / \mathrm{ACN}(1 / 1, \mathrm{v} / \mathrm{v}, \mathrm{CHROMASOLV}$, RiedeldeHaen) was used as an eluent $\left(0.7 \mathrm{~mL} \mathrm{~min}^{-1}\right)$.

5-(2,2':6',2"-Terpyridine-4'-yl)-2,2'-bithiophene. 2,2'-Bithiophene-5-boronic acid pinacol ester (0.509 g, $1.74 \mathrm{mmol})$, Brtpy (0.439 g, $1.41 \mathrm{mmol}), \mathrm{K}_{2} \mathrm{CO}_{3}(0.59 \mathrm{~g}, 4.26 \mathrm{mmol})$ and PEPPSI-IPr (50 mg) were placed in a Schlenk tube. Vacuumargon cycles were applied several times and toluene $(10 \mathrm{~mL})$ and methanol $(10 \mathrm{~mL})$ were added through the septum. The reaction mixture was heated at $90{ }^{\circ} \mathrm{C}$ overnight. After cooling to room temperature the reaction mixture was diluted with dichloromethane $(50 \mathrm{ml})$ and washed with water $(3 \times 200 \mathrm{~mL})$. The organic layer was dried with $\mathrm{MgSO}_{4}$, filtered and evaporated to obtain the crude product. The crude product was contaminated with bithiophene, which was washed off with hexane to obtain the pure product as a yellow powder $(0.53 \mathrm{~g}$, 95\%). ${ }^{1} \mathrm{H}$ NMR (400 MHz, $\left.d_{2}-\mathrm{CD}_{2} \mathrm{Cl}_{2}\right) \delta \mathrm{ppm}$ 8.74-8.72 (m, 2H, $\left.\mathrm{A}^{6}\right), 8.70\left(\mathrm{~s}, 2 \mathrm{H}, \mathrm{B}^{3}\right), 8.67-8.65\left(\mathrm{~m}, 2 \mathrm{H}, \mathrm{A}^{3}\right), 7.90\left(\mathrm{td}, 2 \mathrm{H}, J_{1}=\right.$ 7.7, $\left.J_{2}=1.7, \mathrm{~A}^{4}\right), 7.73-7.71\left(\mathrm{~m}, 1 \mathrm{H}, \mathrm{C}^{4}\right), 7.40-7.37\left(\mathrm{~m}, 2 \mathrm{H}, \mathrm{A}^{5}\right)$, $7.33-7.31\left(\mathrm{~m}, 2 \mathrm{H}, \mathrm{C}^{3}+\mathrm{D}^{5}\right), 7.29\left(\mathrm{~d}, J=3.8,1 \mathrm{H}, \mathrm{D}^{3}\right), 7.10-7.08$ $\left(\mathrm{m}, 1 \mathrm{H}, \mathrm{D}^{4}\right) .{ }^{13} \mathrm{C}$ NMR $\left(101 \mathrm{MHz}, d_{2}-\mathrm{CD}_{2} \mathrm{Cl}_{2}\right) \delta \mathrm{ppm}$ 156.49, 156.10, 149.48, 143.11, 141.15, 140.61, 139.30, 137.15, 128.39, $126.89,125.53,125.10,124.69,124.32,121.36,116.71$. IR (DRIFT), cm ${ }^{-1} 3086$ (m), 3066 (m), 3013 (m), 2988 (w), 2965 (w), 2922 (m), 2871 (w), 2856 (w), 1598 (s), 1583 (s), 1565 (s), 1553 (m), 1541 (m), 1509 (m), 1464 (s), 1435 (m), 1422 (m), 1399 (s), 1366 (w), 1353 (w), 1323 (w), 1306 (w), 1290 (w), 1267 (m), 1253 (w), 1239 (m), 1232 (m), 1227 (m), 1209 (w), $1184(\mathrm{w})$, 1162 (w), 1146 (w), 1124 (m), 1092 (m), 1077 (w), 1064 (m), 1051 (m), $1044(\mathrm{~m}), 1010(\mathrm{~m}), 988(\mathrm{~m}), 961(\mathrm{w}), 954(\mathrm{w}), 915$ (w), $898(\mathrm{w}), 885(\mathrm{~m}), 878(\mathrm{~m}), 838(\mathrm{~m}), 789(\mathrm{~s}), 773(\mathrm{~m}), 746$ (m), $741(\mathrm{~m}), 730(\mathrm{~m}), 717(\mathrm{~s}), 690(\mathrm{~m}), 683(\mathrm{~m}), 668(\mathrm{~m}), 658$ (m), $643(\mathrm{w}), 632(\mathrm{~m}), 622(\mathrm{~m}), 587(\mathrm{w}), 565(\mathrm{w}), 523(\mathrm{~m}), 489$ (m), $466(\mathrm{~m}), 447(\mathrm{w}), 418(\mathrm{w}), 402(\mathrm{~m})$. HRMS found $m / z$ : $420.05998\left[\mathrm{M}^{+} \mathrm{Na}\right]^{+}, \mathrm{C}_{23} \mathrm{H}_{15} \mathrm{~N}_{3} \mathrm{NaS}_{2}$ requires: 420.05996.

5-Bromo-5'-(2,2':6',2"-terpyridine-4'-yl)-2,2'-bithiophene. 5(2,2':6',2"-Terpyridine-4'-yl)-2,2'-bithiophene (0.52 g, $1.31 \mathrm{mmol})$ was dissolved in dichloromethane $(20 \mathrm{~mL})$ and acetic acid $(20 \mathrm{~mL})$, and NBS $(0.26 \mathrm{~g}, 1.46 \mathrm{mmol})$ was added in the dark and the reaction mixture was stirred overnight. Then the acidic mixture was slightly neutralized by using a saturated solution of $\mathrm{K}_{2} \mathrm{CO}_{3}$ in water, diluted with dichloromethane $(40 \mathrm{~mL})$ and washed with water $(3 \times 250 \mathrm{~mL})$. The organic layer was dried with $\mathrm{MgSO}_{4}$, filtered and evaporated to obtain the product as a yellow solid $(0.52 \mathrm{~g}, 83 \%) .{ }^{1} \mathrm{H}$ NMR (400 $\mathrm{MHz}, d_{2}-\mathrm{CD}_{2} \mathrm{Cl}_{2}$ ) $\delta$ ppm 8.74-8.72 (m, 2H, $\left.\mathrm{A}^{6}\right), 8.68-8.65\left(\mathrm{~m}, 4 \mathrm{H}, \mathrm{A}^{3}+\mathrm{B}^{3}\right), 7.90$ $\left(\mathrm{td}, J_{1}=7.8, J_{2}=1.8,2 \mathrm{H}, \mathrm{A}^{4}\right), 7.71\left(\mathrm{~d}, J=3.8,1 \mathrm{H}, \mathrm{C}^{4}\right), 7.38$ 
(ddd, $\left.J_{1}=7.5, J_{2}=4.8, J_{3}=1.2,2 \mathrm{H}, \mathrm{A}^{5}\right), 7.23\left(\mathrm{~d}, J=3.8, \mathrm{C}^{3}\right)$, 7.07-7.05 (m, 2H, D $\left.+\mathrm{D}^{4}\right) .{ }^{13} \mathrm{C}$ NMR (101 MHz, $\left.d_{2}-\mathrm{CD}_{2} \mathrm{Cl}_{2}\right)$ $\delta$ ppm 156.80, 156.30, 149.77, 143.19, 139.04, 138.35, 137.46, 133.99, 131.67, 128.78, 127.18, 125.01, 124.60, 121.67, 121.62, 117.06. IR (DRIFT), $\mathrm{cm}^{-1} 3091$ (m), 3072 (m), 3061 (m), 3051 (m), 3013 (m), 2990 (w), 2962 (m), 2926 (m), 2855 (m), 1735 (w), 1600 (m), 1584 (s), 1566 (s), 1553 (w), 1547 (m), 1515 (m), 1477 (m), 1467 (s), 1438 (w), 1428 (m), 1399 (s), 1369 (w), $1340(\mathrm{w}), 1265(\mathrm{~m}), 1237(\mathrm{~m}), 1223(\mathrm{w}), 1206(\mathrm{w}), 1196(\mathrm{w})$, 1148 (m), 1127 (m), 1100 (m), 1079 (w), 1067 (m), 1042 (m), $1010(\mathrm{~m}), 987(\mathrm{~m}), 973(\mathrm{~m}), 958(\mathrm{w}), 906(\mathrm{w}), 889(\mathrm{w}), 880(\mathrm{~s})$, $874(\mathrm{~s}), 849(\mathrm{w}), 785(\mathrm{~s}), 773(\mathrm{~m}), 752(\mathrm{~m}), 743(\mathrm{~m}), 729(\mathrm{~m})$, $690(\mathrm{~m}), 669(\mathrm{~m}), 659(\mathrm{~m}), 632(\mathrm{~m}), 622(\mathrm{~m}), 581(\mathrm{w}), 556(\mathrm{w})$, 526 (m), 495 (m), 474 (m), 455 (m), 439 (w), 414 (m), 406 (m). HRMS found $m / z: 475.98846\left[\mathrm{M}^{+} \mathrm{H}\right]^{+}, \mathrm{C}_{23} \mathrm{H}_{15} \mathrm{~N}_{3} \mathrm{BrS}_{2}$ requires: 475.98853.

$5,5^{\prime \prime \prime}-\operatorname{Bis}\left(2,2^{\prime}: 6^{\prime}, 2^{\prime \prime}\right.$-terpyridine-4'-yl)-2, $2^{\prime}: 5^{\prime}, 2^{\prime \prime}: 5^{\prime \prime}, 2^{\prime \prime \prime}$-quaterthiophene Q. 5-Bromo-5'-(2,2':6',2"-terpyridine-4'-yl)-2,2'-bithiophene $(0.372 \mathrm{~g}, 0.78 \mathrm{mmol}), \mathrm{B}_{2} \operatorname{pin}_{2}(0.168 \mathrm{~g}, 0.66 \mathrm{mmol})$, $\mathrm{K}_{2} \mathrm{CO}_{3}(0.34 \mathrm{~g}, 2.46 \mathrm{mmol})$ and PEPPSI-IPr $(25 \mathrm{mg})$ were placed in a Schlenk tube and vacuum-argon cycles were applied. Then toluene $(15 \mathrm{~mL})$ and methanol $(15 \mathrm{~mL})$ were added through the septum and the reaction mixture was heated at $90{ }^{\circ} \mathrm{C}$ overnight. After cooling to room temperature the product precipitated. The suspension was filtered, washed with toluene, water and hexane and dried in vacuo. Orange powder (0.18 g, 58\%). ${ }^{1} \mathrm{H}$ NMR (400 $\left.\mathrm{MHz}, d_{2}-\mathrm{CD}_{2} \mathrm{Cl}_{2}\right) \delta \mathrm{ppm}$ 8.75-8.74 (m, $\left.4 \mathrm{H}, \mathrm{A}^{6}\right), 8.71-8.66\left(\mathrm{~m}, 8 \mathrm{H}, \mathrm{A}^{3}+\mathrm{B}^{3}\right), 7.91\left(\mathrm{td}, J_{1}=\right.$ $\left.7.7, J_{2}=1.8,4 \mathrm{H}, \mathrm{A}^{4}\right), 7.75\left(\mathrm{~d}, J=3.9,2 \mathrm{H}, \mathrm{C}^{4}\right), 7.41-7.38(\mathrm{~m}, 4 \mathrm{H}$, $\left.\mathrm{A}^{5}\right), 7.35\left(\mathrm{~d}, J=4.3,2 \mathrm{H}, \mathrm{C}^{3}\right), 7.32-7.21\left(\mathrm{~m}, 4 \mathrm{H}, \mathrm{D}^{3}+\mathrm{D}^{4}\right)$. Due to the low solubility of this compound we were not able to obtain the ${ }^{13} \mathrm{C}$ NMR spectrum in a sufficient quality. IR (DRIFT), $\mathrm{cm}^{-1} 3064(\mathrm{~m}), 3012(\mathrm{~m}), 2991$ (w), 2937 (w), 1718 (w), 1599 (s), 1582 (s), 1567 (s), 1551 (s), 1508 (w), 1476 (m), 1466 (m), $1459(\mathrm{~m}), 1438(\mathrm{~m}), 1400(\mathrm{~m}), 1365(\mathrm{w}), 1327(\mathrm{w}), 1308(\mathrm{w})$, 1292 (w), 1266 (w), 1251 (w), 1237 (w), 1208 (w), $1126(\mathrm{~m}), 1094$ (m), 1079 (w), $1065(\mathrm{~m}), 1042(\mathrm{~m}), 1011(\mathrm{~m}), 988(\mathrm{~m}), 963(\mathrm{w})$, $919(\mathrm{w}), 898(\mathrm{w}), 872(\mathrm{~m}), 855(\mathrm{w}), 849(\mathrm{w}), 786(\mathrm{~s}), 742(\mathrm{~s})$, $732(\mathrm{~m}), 726(\mathrm{~m}), 690(\mathrm{~m}), 683(\mathrm{~m}), 667(\mathrm{~m}), 660(\mathrm{~m}), 640(\mathrm{~m})$, $633(\mathrm{~m}), 621(\mathrm{~m}), 564(\mathrm{w}), 518(\mathrm{w}), 493(\mathrm{~m}), 485(\mathrm{w}), 466(\mathrm{~m})$, $408(\mathrm{~m})$. HRMS found $\mathrm{m} / z$ : $793.13281\left[\mathrm{M}^{+} \mathrm{H}\right]^{+}, \mathrm{C}_{46} \mathrm{H}_{29} \mathrm{~N}_{6} \mathrm{~S}_{4}$ requires: 793.13310 .

$3,3^{\prime \prime \prime}$-Dihexyl-(2,2':5',2":5", $2^{\prime \prime \prime}$-quaterthiophene-5, $5^{\prime \prime \prime}$-diyl)bis(4,4,5,5-tetramethyl-1,3,2-dioxaborolane). 3,3"'-Dihexyl$2,2^{\prime}: 5^{\prime}, 2^{\prime \prime}: 5^{\prime \prime}, 2^{\prime \prime \prime}$-quaterthiophene (0.6 g, $\left.1.2 \mathrm{mmol}\right)$, dtbpy (15 mg, $0.0056 \mathrm{mmol})$ and $\left([\operatorname{Ir}(\mathrm{OMe})(\mathrm{COD})]_{2}\right)(18 \mathrm{mg}$, $0.00271 \mathrm{mmol})$ were placed in a Schlenk tube and vacuumargon cycles were applied. Tetrahydrofuran $(20 \mathrm{~mL})$, hexane $(20 \mathrm{~mL})$ and HBpin $(0.7 \mathrm{~mL}, 0.62 \mathrm{~g}, 4.9 \mathrm{mmol})$ were added and the reaction mixture was heated to $45^{\circ}$ overnight. Then the reaction mixture was poured into water and extracted with dichloromethane. The organic fraction was collected, dried with $\mathrm{MgSO}_{4}$, filtered and evaporated to obtain the product as brownish oil. The product was used without further purification. ${ }^{1} \mathrm{H}$ NMR $\left(300 \mathrm{MHz}, d-\mathrm{CDCl}_{3}\right) \delta \mathrm{ppm} 7.47\left(\mathrm{~s}, 2 \mathrm{H}, \mathrm{C}^{4}\right)$, $7.15\left(\mathrm{~d}, J=3.9,2 \mathrm{H}, \mathrm{D}^{3}\right.$ or $\left.\mathrm{D}^{4}\right), 7.10\left(\mathrm{~d}, J=3.9,2 \mathrm{H}, \mathrm{D}^{4}\right.$ or $\left.\mathrm{D}^{3}\right)$, $2.79\left(\mathrm{t}, J=7.8,4 \mathrm{H}, \mathrm{Hex}^{1}\right), 1.72-1.59\left(\mathrm{~m}, 8 \mathrm{H}, \mathrm{Hex}^{2}+\mathrm{Hex}^{3}\right)$, 1.40-1.25 (m, 32H, $\mathrm{Hex}^{4}+\mathrm{Hex}^{5}+-\mathrm{CH}_{3}$ pinacol ester), 0.92-0.87 (m, 4H, Hex $\left.{ }^{6}\right) .{ }^{13} \mathrm{C}$ NMR (101 MHz, $d_{8}$-THF) $\delta \mathrm{ppm}$ $141.79,141.15,138.20,138.04,136.54,127.89,125.34,84.92$, $32.80,31.70,30.32,30.16,25.24,23.66, \quad 14.6 .{ }^{11} \mathrm{~B} \quad \mathrm{NMR}$ (128.3 MHz, $d_{8}$-THF) $\delta$ ppm 24.19. IR (DRIFT), $\mathrm{cm}^{-1} 3062(\mathrm{w})$, $2976(\mathrm{~m}), 2956(\mathrm{~m}), 2925(\mathrm{~s}), 2871$ (m), $2855(\mathrm{~m}), 1777(\mathrm{w})$, 1730 (w), 1549 (m), 1521 (m), 1460 (s), 1429 (s), 1381 (s), 1372 (s), 1329 (s), 1297 (s), 1269 (s), 1214 (m), 1194 (m), 1166 (m), 1143 (s), 1112 (m), 1060 (w), 1050 (w), 1027 (m), 1002 (w), 983 (w), $961(\mathrm{~m}), 927(\mathrm{w}), 853(\mathrm{~s}), 830(\mathrm{w}), 781(\mathrm{~s}), 741(\mathrm{w}), 725(\mathrm{w})$, $704(\mathrm{w}), 686(\mathrm{~m}), 664(\mathrm{~s}), 607(\mathrm{w}), 579(\mathrm{w}), 522(\mathrm{w}), 437(\mathrm{w})$. HRMS found $m / z: 773.31403\left[\mathrm{M}^{+} \mathrm{Na}\right]^{+}, \quad \mathrm{C}_{40} \mathrm{H}_{56} \mathrm{O}_{4} \mathrm{~B}_{2} \mathrm{NaS}_{4}$ requires: 773.31398 .

3,3"'-Dihexyl-5, 5"'-bis(2,2':6',2"-terpyridine-4'-yl)-2,2':5',2":5",2"'quaterthiophene Q27-H. 3,3"'-Dihexyl-(2,2':5',2":5",2"'-quaterthiophene-5, $5^{\prime \prime \prime}$-diyl)-bis(4,4,5,5-tetramethyl-1,3,2-dioxaborolane) (0.58 g, $0.77 \mathrm{mmol}$ ), Brtpy (0.488 g, $1.56 \mathrm{mmol}), \mathrm{K}_{2} \mathrm{CO}_{3}$ $(0.34 \mathrm{~g}, 2.46 \mathrm{mmol})$ and PEPPSI-IPr $(36 \mathrm{mg})$ were placed in a Schlenk tube and vacuum-argon cycles were applied. Toluene $(15 \mathrm{~mL})$ and methanol $(15 \mathrm{~mL})$ were added through the septum and the reaction mixture was heated to $90{ }^{\circ} \mathrm{C}$ overnight. After cooling to room temperature the mixture was diluted with dichloromethane $(30 \mathrm{~mL})$ and washed with water $(3 \times 200 \mathrm{~mL})$. The organic layer was dried with $\mathrm{MgSO}_{4}$, filtered and evaporated to obtain the crude product. The product was purified by column chromatography $\left(\mathrm{Al}_{2} \mathrm{O}_{3}\right.$, hexane/THF, $\left.3: 2\right)$. Orange powder $(0.12 \mathrm{~g}, 17 \%) .{ }^{1} \mathrm{H} \mathrm{NMR}\left(400 \mathrm{MHz}, d-\mathrm{CDCl}_{3}\right)$ $\delta$ ppm 8.78-8.76 (m, $\left.4 \mathrm{H}, \mathrm{A}^{6}\right), 8.68\left(\mathrm{~s}, 4 \mathrm{H}, \mathrm{B}^{3}\right), 8.65\left(\mathrm{~m}, 4 \mathrm{H}, \mathrm{A}^{3}\right)$, $7.89\left(\mathrm{td}, J_{1}=7.7, J_{2}=1.7,4 \mathrm{H}, \mathrm{A}^{4}\right), 7.66\left(\mathrm{~s}, 2 \mathrm{H}, \mathrm{C}^{4}\right), 7.38(\mathrm{ddd}$, $\left.J_{1}=7.5, J_{2}=4.7, J_{3}=1.3,4 \mathrm{H}, \mathrm{A}^{5}\right), 7.21\left(\mathrm{~d}, J=3.9,2 \mathrm{H}, \mathrm{D}^{3}\right.$ or $\left.\mathrm{D}^{4}\right)$, $7.17\left(\mathrm{~d}, J=3.9, \mathrm{D}^{4}\right.$ or $\left.\mathrm{D}^{3}\right), 2.87\left(\mathrm{t}, J=3.9,4 \mathrm{H}, \mathrm{Hex}^{1}\right), 1.82-1.72$ $\left(\mathrm{m}, 4 \mathrm{H}, \mathrm{Hex}^{2}\right), 1.50-1.36\left(\mathrm{~m}, 12 \mathrm{H}, \mathrm{Hex}^{3}-\mathrm{Hex}^{5}\right), 0.97-0.89$ $\left(\mathrm{m}, 4 \mathrm{H}, \mathrm{Hex}^{6}\right) .{ }^{13} \mathrm{C}$ NMR $\left(101 \mathrm{MHz}, d-\mathrm{CDCl}_{3}\right) \delta \mathrm{ppm}$ 156.05, 149.14, 142.96, 140.96, 139.17, 137.10, 136.87, 135.09, 132.42, $128.91,126.85,124.17,123.92,121.35,116.59,31.69,30.57$, 29.73, 29.73, 22.64, 14.13. IR (DRIFT), $\mathrm{cm}^{-1} 3063$ (m), 3013 (w), 2957 (m), 2925 (s), 2852 (m), 1974 (w), 1955 (w), $1724(\mathrm{~m}), 1599$ (s), 1583 (s), 1567 (s), 1544 (m), 1468 (s), 1458 (s), 1434 (m), 1403 (s), 1386 (m), 1361 (m), 1340 (w), $1298(\mathrm{w}), 1265(\mathrm{~m}), 1254(\mathrm{~m}), 1210(\mathrm{~m}), 1195(\mathrm{w}), 1177(\mathrm{w})$, 1146 (w), 1124 (m), 1093 (m), 1070 (m), 1037 (m), 1021 (m), $990(\mathrm{~m}), 970(\mathrm{w}), 918(\mathrm{w}), 897(\mathrm{w}), 879(\mathrm{~m}), 848(\mathrm{~m}), 839(\mathrm{~m})$, $789(\mathrm{~s}), 776(\mathrm{~s}), 742(\mathrm{~s}), 728(\mathrm{~m}), 715(\mathrm{w}), 693(\mathrm{w}), 682(\mathrm{~m})$, $663(\mathrm{~m}), 658(\mathrm{~m}), 642(\mathrm{~m}), 631(\mathrm{~m}), 622(\mathrm{~m}), 585(\mathrm{w}), 566(\mathrm{w})$, $524(\mathrm{w}), 501(\mathrm{~m}), 461(\mathrm{w}), 403(\mathrm{~m})$. HRMS found $\mathrm{m} / \mathrm{z}: 961.32106$ $\left[\mathrm{M}^{+} \mathrm{H}\right]^{+}, \mathrm{C}_{58} \mathrm{H}_{33} \mathrm{~N}_{6} \mathrm{~S}_{4}$ requires: 961.32090 .

$3,3^{\prime \prime \prime}-\operatorname{Bis}(6-(4-m e t h o x y p h e n o x y) h e x y l)-2,2^{\prime}: 5^{\prime}, 2^{\prime \prime}: 5^{\prime \prime}, 2^{\prime \prime \prime}$-quaterthiophene. 2-Bromo-3-(6-(4-methoxyphenoxy)hexyl)thiophene (3.5 g, 9.5 mmol), 5,5'-bis(4,4,5,5-tetramethyl-1,3,2-dioxaborolan-2-yl)-2,2'-bithiophene (1.4 g, $4.8 \mathrm{mmol}), \mathrm{K}_{2} \mathrm{CO}_{3}(3.94 \mathrm{~g}$, $28.5 \mathrm{mmol})$, and PEPPSI-IPr $(150 \mathrm{mg}$ ) were introduced into a pre-dried Schlenk tube with a magnetic stirring bar and vacuum-argon cycles were applied. A mixed solvent (toluene/ methanol, 1:1) was added and the reaction mixture was heated at $90^{\circ} \mathrm{C}$ for 24 hours. After cooling to room temperature 
the reaction mixture was extracted with dichloromethane, the organic phase was dried with $\mathrm{MgSO}_{4}$, filtered off and evaporated. The crude product was purified by precipitation from concentrated THF solution by using hexane. Orange powder (3.4 g, 97\%). ${ }^{1} \mathrm{H}$ NMR (400 MHz, $\left.d-\mathrm{CDCl}_{3}\right) \delta \mathrm{ppm} 7.19(\mathrm{~d}, J=$ $5.2,2 \mathrm{H}, \mathrm{C}^{4}$ or $\left.\mathrm{C}^{5}\right), 7.12\left(\mathrm{~d}, J=3.8,2 \mathrm{H}, \mathrm{D}^{3}\right.$ or $\left.\mathrm{D}^{4}\right), 7.01(\mathrm{~d}, J=$ $3.8,2 \mathrm{H}, \mathrm{D}^{4}$ or $\left.\mathrm{D}^{3}\right), 6.95\left(\mathrm{~d}, J=5.2,2 \mathrm{H}, \mathrm{C}^{5}\right.$ or $\left.\mathrm{C}^{4}\right), 6.81-6.83(\mathrm{~m}$, $8 \mathrm{H},-\mathrm{Ph}), 3.90\left(\mathrm{t}, J=6.6,4 \mathrm{H}, \mathrm{Hex}^{6}\right), 3.76\left(\mathrm{~s}, 6 \mathrm{H},-\mathrm{OCH}_{3}\right), 2.81$ $\left(\mathrm{t}, J=7.9,4 \mathrm{H}, \mathrm{Hex}^{1}\right), 1.65-1.81\left(\mathrm{~m}, 8 \mathrm{H}, \mathrm{Hex}^{2}+\mathrm{Hex}^{5}\right), 1.41-1.51$ $\left(\mathrm{m}, 8 \mathrm{H}, \mathrm{Hex}^{3}+\mathrm{Hex}^{4}\right) \cdot{ }^{13} \mathrm{C} \mathrm{NMR}\left(101 \mathrm{MHz}, d-\mathrm{CDCl}_{3}\right) \delta \mathrm{ppm}$ 160.43, 153.65, 153.24, 150.09, 144.13, 139.65, 135.24, 130.39, 126.60, 123.86, 115.41, 114.60, 69.10, 68.54, 30.53, 29.31, 29.18, 27.14, 25.87. IR (DRIFT), $\mathrm{cm}^{-1} 3096$ (m), 3070 (m), 3056 (m), 3042 (w), 3001 (m), 2937 (s), 2928 (s), 2855 (s), 2834 (m), $2067(\mathrm{w}), 1857(\mathrm{w}), 1750(\mathrm{~m}), 1615(\mathrm{w}), 1591(\mathrm{~m}), 1539(\mathrm{w})$, 1508 (s), 1495 (m), 1467 (m), 1456 (m), 1442 (m), 1422 (m), 1389 (m), 1378 (w), 1347 (w), 1322 (m), 1308 (m), 1294 (m), 1231 (s), 1193 (s), 1176 (m), 1154 (w), 1146 (w), 1108 (m), $1090(\mathrm{~m}), 1071(\mathrm{~s}), 1056(\mathrm{~m}), 1038(\mathrm{~s}), 1005(\mathrm{w}), 989(\mathrm{~s})$, $958(\mathrm{w}), 940(\mathrm{~m}), 929(\mathrm{~m}), 919(\mathrm{~m}), 906(\mathrm{w}), 889(\mathrm{w}), 876(\mathrm{~m})$, $855(\mathrm{~m}), 826(\mathrm{~s}), 805(\mathrm{~s}), 792(\mathrm{~s}), 757(\mathrm{~m}), 742(\mathrm{~s}), 722(\mathrm{~m})$, $699(\mathrm{~m}), 687(\mathrm{~m}), 669(\mathrm{~m}), 654(\mathrm{~m}), 638(\mathrm{w}), 631(\mathrm{w}), 599(\mathrm{w})$, $586(\mathrm{w}), 566(\mathrm{w}), 521(\mathrm{~s}), 506(\mathrm{~m}), 472(\mathrm{w}), 462(\mathrm{~m}), 426(\mathrm{w})$. HRMS found $m / z$ : $765.21732\left[\mathrm{M}^{+} \mathrm{Na}\right]^{+}, \mathrm{C}_{42} \mathrm{H}_{46} \mathrm{O}_{4} \mathrm{NaS}_{4}$ requires: 765.21711.

$5,5^{\prime \prime \prime}-\left(3,3^{\prime \prime \prime}-\operatorname{Bis}\left(6-(4-m e t h o x y p h e n o x y) h e x y l-2,2^{\prime}: 5^{\prime}, 2^{\prime \prime}: 5^{\prime \prime}, 2^{\prime \prime \prime}-\right.\right.$ quaterthiophene-5,5"'-diyl)bis (4,4,5,5-tetramethyl-1,3,2-dioxa-

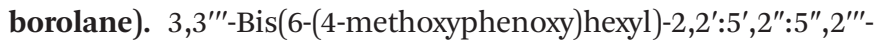
quaterthiophene $(0.6 \mathrm{~g}, 0.8 \mathrm{mmol})$, dtbpy (9 mg, $0.03 \mathrm{mmol})$ and $\left([\mathrm{Ir}(\mathrm{OMe})(\mathrm{COD})]_{2}\right)(9 \mathrm{mg}, 0.01 \mathrm{mmol})$ were placed in a tube and vacuum-argon cycles were applied. Tetrahydrofuran (12 $\mathrm{mL})$, hexane (12 mL) and HBpin (0.24 mL, $0.21 \mathrm{~g}$, $2.1 \mathrm{mmol})$ were added. The tube was heated at $50{ }^{\circ} \mathrm{C}$ for 24 hours. After opening the tube, water was added and the mixture was stirred for an hour. Then the reaction mixture was extracted with dichloromethane, the organic phase was dried with $\mathrm{MgSO}_{4}$, filtered off and evaporated to obtain the product $(0.76 \mathrm{~g}, 95 \%)$. The product was used as obtained for the following synthesis without purification. ${ }^{1} \mathrm{H}$ NMR $(400 \mathrm{MHz}$, $\left.d-\mathrm{CDCl}_{3}\right) \delta$ ppm $7.47\left(\mathrm{~s}, 2 \mathrm{H}, \mathrm{C}^{4}\right), 7.13\left(\mathrm{~d}, J=3.9,2 \mathrm{H}, \mathrm{D}^{3}\right.$ or $\left.\mathrm{D}^{4}\right)$, $7.07\left(\mathrm{~d}, J=3.9,2 \mathrm{H}, \mathrm{D}^{4}\right.$ or $\left.\mathrm{D}^{3}\right), 6.82(\mathrm{~s}, 8 \mathrm{H},-\mathrm{Ph}), 3.89(\mathrm{t}, J=6.6$, $\left.4 \mathrm{H}, \mathrm{Hex}^{6}\right), 3.76\left(\mathrm{~s}, 6 \mathrm{H},-\mathrm{OCH}_{3}\right), 2.81\left(\mathrm{t}, J=7.4,4 \mathrm{H}, \mathrm{Hex}^{1}\right)$, 1.80-1.69 (m, 8H, $\left.\mathrm{Hex}^{2}+\mathrm{Hex}^{5}\right), 1.52-1.44\left(\mathrm{~m}, 8 \mathrm{H}, \mathrm{Hex}^{3}+\right.$ $\left.\mathrm{Hex}^{4}\right), 1.36$ (s, 24H, $-\mathrm{CH}_{3}$ pinacol ester). ${ }^{13} \mathrm{C}$ NMR (101 MHz, $\left.d-\mathrm{CDCl}_{3}\right) \delta$ ppm 153.64, 153.25, 140.70, 140.09, 137.53, 137.07, 135.30, 126.85, 124.10, 115.41, 114.59, 84.18, 68.56, 55.71, $30.44,29.29,29.26,29.12,25.88,24.75,24.59 .{ }^{11} \mathrm{~B}$ NMR (128.3 MHz, $d-\mathrm{CDCl}_{3}$ ) $\delta \mathrm{ppm} 22.50$. IR (DRIFT), $\mathrm{cm}^{-1} 3092(\mathrm{w})$, $2975(\mathrm{~m}), 2936$ (m), 2861 (m), 2833 (w), $1752(\mathrm{w}), 1617(\mathrm{w})$, $1593(\mathrm{w}), 1544$ (w), 1508 (s), 1471 (m), 1456 (m), 1380 (m), $1372(\mathrm{~m}), 1334(\mathrm{~m}), 1306(\mathrm{~m}), 1266(\mathrm{~m}), 1231(\mathrm{~s}), 1180(\mathrm{~m})$, 1167 (m), 1143 (m), 1107 (m), 1073 (m), 1039 (m), 1009 (m), $983(\mathrm{~m}), 967(\mathrm{w}), 926(\mathrm{w}), 902(\mathrm{w}), 851(\mathrm{~m}), 825(\mathrm{~m}), 793(\mathrm{~m})$, $743(\mathrm{~m}), 721(\mathrm{~m}), 700(\mathrm{~m}), 674(\mathrm{~m}), 606(\mathrm{w}), 578(\mathrm{w}), 522(\mathrm{~m})$. HRMS found $m / z: 1017.38703\left[\mathrm{M}^{+} \mathrm{Na}\right]^{+}, \quad \mathrm{C}_{54} \mathrm{H}_{68} \mathrm{O}_{8} \mathrm{~B}_{2} \mathrm{NaS}_{4}$ requires: 1017.38753 .
3,3"'-Bis(6-(4-methoxyphenoxy)hexyl)-5, $5^{\prime \prime \prime}-\operatorname{bis}\left(2,2^{\prime}: 6^{\prime}, 2^{\prime \prime}-\right.$

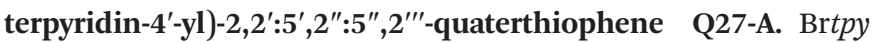
(0.33 g, $1.03 \mathrm{mmol}), \mathrm{K}_{2} \mathrm{CO}_{3}(0.20 \mathrm{~g}, 1.47 \mathrm{mmol})$ and PEPPSI-IPr (20 $\mathrm{mg})$ were placed in a pre-dried Schlenk tube and three vacuum-argon cycles were applied. 5,5'"'-(3,3'"'-Bis(6-(4-methoxy-

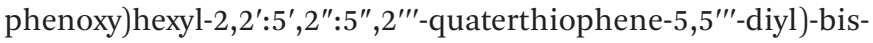
(4,4,5,5-tetramethyl-1,3,2-dioxaborolane) (0.47 g, $0.47 \mathrm{mmol}$ ) was dissolved in toluene $(15 \mathrm{~mL})$ and added to the tube. Methanol (15 mL) was added and the reaction mixture was heated at $90{ }^{\circ} \mathrm{C}$ for 24 hours. After cooling to room temperature the mixture was extracted with dichloromethane, the organic phase was dried with $\mathrm{MgSO}_{4}$, filtered off and evaporated. The crude product was purified by column chromatography $\left(\mathrm{Al}_{2} \mathrm{O}_{3}\right.$, hexane/THF, $\left.3: 2\right)$ to obtain the product as an orange solid $(0.18 \mathrm{~g}, 32 \%) .{ }^{1} \mathrm{H}$ NMR $\left(400 \mathrm{MHz}, d-\mathrm{CDCl}_{3}\right) \delta \mathrm{ppm}$ 8.75-8.78 (m, $\left.4 \mathrm{H}, \mathrm{A}^{6}\right), 8.68-8.65\left(\mathrm{~m}, 8 \mathrm{H}, \mathrm{B}^{3}+\mathrm{A}^{3}\right), 7.89\left(\mathrm{td}, J_{1}=\right.$ $\left.8.0, J_{2}=1.8,4 \mathrm{H}, \mathrm{A}^{4}\right), 7.66\left(\mathrm{~s}, 2 \mathrm{H}, \mathrm{C}^{4}\right), 7.38\left(\mathrm{ddd}, J_{1}=7.6, J_{2}=\right.$ $\left.4.9, J_{2}=1.5,4 \mathrm{H}, \mathrm{A}^{5}\right), 7.19\left(\mathrm{~d}, J=3.8,2 \mathrm{H}, \mathrm{D}^{3}\right.$ or $\left.\mathrm{D}^{4}\right), 7.14(\mathrm{~d}, J=$ $4.10,2 \mathrm{H}, \mathrm{D}^{4}$ or $\left.\mathrm{D}^{3}\right), 6.79-6.86(\mathrm{~m}, 8 \mathrm{H},-\mathrm{Ph}), 3.93(\mathrm{t}, J=6.3,4 \mathrm{H}$, $\left.\mathrm{Hex}^{6}\right), 3.75\left(\mathrm{~s}, 6 \mathrm{H},-\mathrm{OCH}_{3}\right), 2.88\left(\mathrm{t}, J=7.9,4 \mathrm{H}, \mathrm{Hex}^{1}\right), 1.76-1.86$ $\left(\mathrm{m}, 8 \mathrm{H}, \mathrm{Hex}^{2}+\mathrm{Hex}^{5}\right), 1.52-1.59\left(\mathrm{~m}, 8 \mathrm{H}, \mathrm{Hex}^{3}+\mathrm{Hex}^{4}\right) .{ }^{13} \mathrm{C} \mathrm{NMR}$ $\left(101 \mathrm{MHz}, d-\mathrm{CDCl}_{3}\right) \delta \mathrm{ppm} 156.07,156.03,153.65,153.27$, 149.14, 142.91, 140.72, 139.27, 137.10, 136.86, 135.00, 132.48, 128.84, 126.93, 124.22, 123.92, 121.33, 116.53, 115.44, 114.59, $68.56,55.72,30.47,29.57,29.34,29.32,25.94$. IR (DRIFT), $\mathrm{cm}^{-1} 3060(\mathrm{~m}), 3050(\mathrm{~m}), 3011(\mathrm{w}), 2930$ (s), 2858 (m), 1601 (s), 1584 (s), 1568 (s), 1545 (m), 1508 (s), 1466 (s), 1441 (m), 1401 (s), 1384 (w), $1334(\mathrm{w}), 1303$ (w), 1289 (w), 1263 (m), 1231 (s), 1181 (m), 1146 (w), 1123 (m), 1105 (m), 1095 (m), 1071 (m), $1039(\mathrm{~m}), 1019(\mathrm{~m}), 990(\mathrm{~m}), 882(\mathrm{~m}), 831$ (m), $823(\mathrm{~m}), 787(\mathrm{~s}), 774(\mathrm{~m}), 740(\mathrm{~m}), 726(\mathrm{~m}), 706(\mathrm{w}), 670(\mathrm{w})$, $660(\mathrm{~m}), 630(\mathrm{~m}), 622(\mathrm{~m}), 567(\mathrm{w}), 525(\mathrm{w}), 498(\mathrm{w}), 468(\mathrm{w})$, $425(\mathrm{w}), 400(\mathrm{~m})$. HRMS found $m / z: 1205.39458\left[\mathrm{M}^{+} \mathrm{H}\right]^{+}$, $\mathrm{C}_{72} \mathrm{H}_{65} \mathrm{O}_{4} \mathrm{~N}_{6} \mathrm{~S}_{4}$ requires: 1205.39446 .

3,3'-Bis(6-(4-methoxyphenoxy)hexyl-2,2'-bithiophene. 2-Bromo3-(6-(4-methoxyphenoxy)hexyl)thiophene (1.66 g, $4.5 \mathrm{mmol}$ ), $\mathrm{B}_{2} \operatorname{pin}_{2}(0.71 \mathrm{~g}, 2.8 \mathrm{mmol}), \mathrm{K}_{2} \mathrm{CO}_{3}(1.8 \mathrm{~g}, 13 \mathrm{mmol})$ and PEPPSI-IPr (112 mg) were placed in a Schlenk tube and vacuum-argon cycles were applied. Toluene $(16 \mathrm{~mL})$ and methanol $(16 \mathrm{~mL})$ were added and the reaction mixture was heated at $90{ }^{\circ} \mathrm{C}$ for 24 hours. After cooling to room temperature the reaction mixture was extracted with dichloromethane, the organic phase was dried with $\mathrm{MgSO}_{4}$, filtered off and evaporated. The crude product was purified by column chromatography ( $\mathrm{SiO}_{2}$, hexane $\left./ \mathrm{CH}_{2} \mathrm{Cl}_{2}, 1: 1\right)$ to obtain the pure product $(0.62 \mathrm{~g}, 48 \%) .{ }^{1} \mathrm{H}$ NMR $\left(300 \mathrm{MHz}, d-\mathrm{CDCl}_{3}\right) \delta \mathrm{ppm}$ $7.29\left(\mathrm{~d}, J=5.4,2 \mathrm{H}, \mathrm{D}^{4}\right.$ or $\left.\mathrm{D}^{5}\right), 6.96\left(\mathrm{~d}, J=5.1,2 \mathrm{H}, \mathrm{D}^{5}\right.$ or $\left.\mathrm{D}^{4}\right)$, $6.82(\mathrm{~s}, 8 \mathrm{H},-\mathrm{Ph}), 3.84\left(\mathrm{t}, J=6.5,4 \mathrm{H}, \operatorname{Hex}^{6}\right), 3.77(\mathrm{~s}, 6 \mathrm{H}$, $\left.-\mathrm{OCH}_{3}\right), 2.52\left(\mathrm{t}, J=7.7,4 \mathrm{H}, \mathrm{Hex}^{1}\right), 1.74-1.67\left(\mathrm{~m}, 4 \mathrm{H}, \mathrm{Hex}^{5}\right)$, 1.63-1.56 (m, 4H, $\operatorname{Hex}^{2}$ ), 1.44-1.29 (m, 8H, Hex $\left.{ }^{3}+\mathrm{Hex}^{4}\right)$.

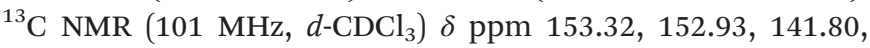
$128.43,128.19,125.0,115.08,114.27,68.21,55.43,30.29$, 28.94, 28.77, 28.34, 25.49. IR (DRIFT), $\mathrm{cm}^{-1} 3107$ (m), $3064(\mathrm{~m}), 3046(\mathrm{~m}), 3011(\mathrm{~m}), 2932(\mathrm{~s}), 2854(\mathrm{~s}), 2836(\mathrm{~m})$, 1510 (s), 1476 (m), 1466 (m), 1442 (m), 1395 (m), 1379 (w), 1349 (w), 1335 (w), 1291 (s), 1269 (m), 1239 (s), 1179 (m), 
$1154(\mathrm{w}), 1130$ (w), $1109(\mathrm{~m}), 1090$ (m), 1073 (w), 1038 (s), $1016(\mathrm{~m}), 1001(\mathrm{~m}), 943(\mathrm{w}), 932(\mathrm{~m}), 915(\mathrm{~m}), 894(\mathrm{~m})$, $884(\mathrm{~m}), 826(\mathrm{~s}), 789(\mathrm{w}), 767(\mathrm{w}), 742(\mathrm{~s}), 732(\mathrm{~m}), 717(\mathrm{~s})$, $695(\mathrm{~m}), 686(\mathrm{~m}), 663(\mathrm{~m}), 629(\mathrm{~m}), 602(\mathrm{w}), 571(\mathrm{w}), 531(\mathrm{~m})$, $521(\mathrm{~m}), 509(\mathrm{~m}), 490(\mathrm{w}), 436(\mathrm{w}), 422(\mathrm{w})$. HRMS found $\mathrm{m} / \mathrm{z}$ : 579.25984 $\left[\mathrm{M}^{+} \mathrm{H}\right]^{+}, \mathrm{C}_{34} \mathrm{H}_{43} \mathrm{O}_{4} \mathrm{~S}_{2}$ requires: 579.25973.

5,5'-(3,3'-Bis(6-(4-methoxyphenoxy)hexyl-2,2'-bithiophene5,5'-diyl)bis(4,4,5,5-tetramethyl-1,3,2-dioxaborolane). 3,3'Bis-(6-(4-methoxyphenoxy)hexyl-2,2'-bithiophene (0.6 g, $1.0 \mathrm{mmol})$, dtbpy (46 mg, $0.17 \mathrm{mmol})$ and ([Ir(OMe)(COD) $\left.]_{2}\right)$ (48 mg, $0.07 \mathrm{mmol})$ were placed in a tube and vacuum-argon cycles were applied. Tetrahydrofuran $(15 \mathrm{~mL})$, hexane $(15 \mathrm{~mL})$ and HBpin $(0.6 \mathrm{~mL}, 0.53 \mathrm{~g}, 4.2 \mathrm{mmol})$ were added through septum. The tube was heated at $50{ }^{\circ} \mathrm{C}$ for 4 days. After opening the tube, water was added and the solution was stirred for an hour. Then the reaction mixture was extracted with dichloromethane, the organic phase was dried with $\mathrm{MgSO}_{4}$, filtered off and evaporated to obtain the product $(0.88 \mathrm{~g}, 100 \%)$. The product was used as obtained for the following synthesis without purification. ${ }^{1} \mathrm{H} \mathrm{NMR}\left(300 \mathrm{MHz}, d-\mathrm{CDCl}_{3}\right) \delta \mathrm{ppm} 7.52$ $\left(\mathrm{s}, 2 \mathrm{H}, \mathrm{D}^{4}\right), 6.82(\mathrm{~s}, 8 \mathrm{H},-\mathrm{Ph}), 3.85\left(\mathrm{t}, J=6.5,4 \mathrm{H}, \mathrm{Hex}^{6}\right), 3.77(\mathrm{~s}$, $\left.6 \mathrm{H},-\mathrm{OCH}_{3}\right), 2.53\left(\mathrm{t}, J=7.7,4 \mathrm{H}, \mathrm{Hex}^{1}\right), 1.88-1.84\left(\mathrm{~m}, 4 \mathrm{H}, \mathrm{Hex}^{5}\right)$, 1.72-1.68 (m, 4H, $\mathrm{Hex}^{2}$ ), 1.60-1.54 (m, 4H, $\mathrm{Hex}^{3}$ ), 1.42-1.30 $\left(\mathrm{m}, 28 \mathrm{H}, \mathrm{Hex}^{4}+-\mathrm{CH}_{3}\right.$ pinacol ester). ${ }^{13} \mathrm{C} \mathrm{NMR}(101 \mathrm{MHz}$, $\left.d-\mathrm{CDCl}_{3}\right) \delta \mathrm{ppm} 153.59,153.25,143.42,138.71,136.29,128.71$, 115.41, 114.58, 84.10, 68.55, 55.74, 30.56, 29.24, 29.10, 28.57, 25.82, 24.76. ${ }^{11} \mathrm{~B}$ NMR (128.3 MHz, $\left.d-\mathrm{CDCl}_{3}\right) \delta \mathrm{ppm} \mathrm{22.48.}$ IR (DRIFT), cm $\mathrm{cm}^{-1} 3045$ (w), 2977 (s), 2934 (s), 2857 (s), $2833(\mathrm{~m}), 1615$ (w), 1591 (m), 1532 (m), 1508 (s), 1470 (m), 1456 (m), 1435 (m), 1380 (m), 1373 (m), 1329 (m), 1296 (m), 1268 (m), 1232 (s), $1180(\mathrm{w}), 1167$ (w), 1142 (s), 1107 (m), $1074(\mathrm{w}), 1039(\mathrm{~m}), 984(\mathrm{w}), 961(\mathrm{~m}), 925(\mathrm{w}), 853(\mathrm{~m}), 825(\mathrm{~m})$, $802(\mathrm{~m}), 773(\mathrm{w}), 742(\mathrm{~m}), 723(\mathrm{~m}), 686(\mathrm{~m}), 665(\mathrm{~s}), 605(\mathrm{w})$, $578(\mathrm{~m}), 523(\mathrm{~m}), 436(\mathrm{w})$. HRMS found $\mathrm{m} / \mathrm{z}: 853.41211$ $\left[\mathrm{M}^{+} \mathrm{Na}\right]^{+}, \mathrm{C}_{46} \mathrm{H}_{64} \mathrm{O}_{8} \mathrm{~B}_{2} \mathrm{NaS}_{2}$ requires: 853.41209.

4',3"-Bis(6-(4-methoxyphenoxy)hexyl-5, 5'"'-bis(2,2':6', 2"terpyridine-4'-yl)-2,2':5',2":5", $2^{\prime \prime \prime}$-quaterthiophene Q45-A. 4'-(5Bromothiophene-2-yl)-2,2':6'2"-terpyridine (0.6 g, $1.62 \mathrm{mmol}$ ), $\mathrm{K}_{2} \mathrm{CO}_{3}(0.78 \mathrm{~g}, 5.6 \mathrm{mmol})$ and PEPPSI (54 mg) were placed in a Schlenk tube and vacuum-argon cycles were applied. 5,5'-(3,3'Bis(6-(4-methoxyphenoxy)hexyl-2,2'-bithiophene-5,5'-diyl)bis(4,4,5,5-tetramethyl-1,3,2-dioxaborolane) (0.68 g, $0.8 \mathrm{mmol})$ was dissolved in toluene $(16 \mathrm{~mL})$ and added to the tube. Methanol $(16 \mathrm{~mL})$ was added and the reaction mixture was heated at $95{ }^{\circ} \mathrm{C}$ for 20 hours. After cooling to room temperature the mixture was extracted with dichloromethane, and the organic phase was dried with $\mathrm{MgSO}_{4}$, filtered off and evaporated. The crude product was purified by column chromatography $\left(\mathrm{Al}_{2} \mathrm{O}_{3}\right.$, hexane/THF $\left.3: 2\right)$ to obtain the product as an orange solid $(0.28 \mathrm{~g}, 28 \%) .{ }^{1} \mathrm{H}$ NMR $(400 \mathrm{MHz}$, $\left.d-\mathrm{CDCl}_{3}\right) \delta \mathrm{ppm} 8.77-8.75\left(\mathrm{~m}, 4 \mathrm{H}, \mathrm{A}^{6}\right), 8.70\left(\mathrm{~s}, 4 \mathrm{H}, \mathrm{B}^{3}\right), 8.67$ $\left(\mathrm{dt}, J_{1}=8.0, J_{2}=1.1,4 \mathrm{H}, \mathrm{A}^{3}\right), 7.89\left(\mathrm{td}, J_{1}=7.8, J_{2}=1.8,4 \mathrm{H}\right.$, $\left.\mathrm{A}^{4}\right), 7.71\left(\mathrm{~d}, J=7.3,2 \mathrm{H}, \mathrm{C}^{4}\right), 7.38\left(\mathrm{ddd}, J_{1}=7.4, J_{2}=4.8, J_{3}=\right.$ $\left.1.4,4 \mathrm{H}, \mathrm{A}^{5}\right), 7.24\left(\mathrm{~d}, J=3.6,2 \mathrm{H}, \mathrm{C}^{3}\right), 7.19\left(\mathrm{~s}, 2 \mathrm{H}, \mathrm{D}^{4}\right), 6.8(\mathrm{~s}$, $4 \mathrm{H},-\mathrm{Ph}), 6.79(\mathrm{~s}, 4 \mathrm{H},-\mathrm{Ph}), 3.89\left(\mathrm{t}, J=6.5,4 \mathrm{H}, \mathrm{Hex}^{6}\right), 3.71(\mathrm{~s}$, $6 \mathrm{H},-\mathrm{OMe}), 2.61\left(\mathrm{t}, J=7.6,4 \mathrm{H}, \mathrm{Hex}^{1}\right), 1.80-1.73(\mathrm{~m}, 4 \mathrm{H}$,
$\left.\mathrm{Hex}^{5}\right), 1.70-1.64\left(\mathrm{~m}, 4 \mathrm{H}, \mathrm{Hex}^{2}\right), 1.50-1.40\left(\mathrm{~m}, 8 \mathrm{H}, \mathrm{Hex}^{3}+\right.$ $\left.\mathrm{Hex}^{4}\right) .{ }^{13} \mathrm{C}$ NMR (101 MHz, $\left.d-\mathrm{CDCl}_{3}\right) \delta \mathrm{ppm} \mathrm{156.12,} \mathrm{155.99,}$ $153.60,153.26,149.16,143.53,142.98,140.34,138.88$, $136.86,136.23,127.99,126.64,125.88,124.62,123.92$, $121.30,116.66,115.38,114.57,68.54,55.66,30.52,29.28$, 29.06, 28.89, 25.84. IR (DRIFT), $\mathrm{cm}^{-1} 3064$ (m), 3049 (m), $3004(\mathrm{~m}), 2936$ (s), $2859(\mathrm{~m}), 2831$ (w), $1599(\mathrm{~m}), 1582$ (s), 1566 (m), 1552 (m), 1507 (s), 1466 (s), 1446 (m), 1399 (m), $1382(\mathrm{w}), 1362$ (w), 1303 (w), 1290 (w), 1265 (m), 1231 (s), 1181 (m), 1152 (w), 1146 (w), 1125 (w), 1107 (m), 1095 (m), $1085(\mathrm{w}), 1065(\mathrm{~m}), 1038(\mathrm{~m}), 1011(\mathrm{~m}), 990(\mathrm{~m}), 946(\mathrm{w})$, $919(\mathrm{w}), 907(\mathrm{w}), 882(\mathrm{~m}), 878(\mathrm{~m}), 862(\mathrm{w}), 848(\mathrm{w}), 825(\mathrm{~s})$, $789(\mathrm{~s}), 773(\mathrm{~m}), 743(\mathrm{~m}), 729(\mathrm{~m}), 720(\mathrm{~m}), 701(\mathrm{w}), 680(\mathrm{~m})$, $658(\mathrm{~m}), 633(\mathrm{~m}), 622(\mathrm{~m}), 584(\mathrm{w}), 565(\mathrm{w}), 535(\mathrm{w}), 523(\mathrm{~m})$, $506(\mathrm{w}), 494(\mathrm{w}), 468(\mathrm{w}), 456(\mathrm{w}), 418$ (w), 403 (m). HRMS found $m / z: 1205.39479\left[\mathrm{M}^{+} \mathrm{H}\right]^{+}, \mathrm{C}_{72} \mathrm{H}_{65} \mathrm{O}_{4} \mathrm{~N}_{6} \mathrm{~S}_{4}$ requires: 1205.39446.

$3,4^{\prime}, 3^{\prime \prime}, 3^{\prime \prime \prime}-$ Tetra(6-(4-methoxyphenoxy)hexyl)-2,2':5', $2^{\prime \prime}: 5^{\prime \prime}, 2^{\prime \prime \prime}-$ quaterthiophene. 5,5'-(3,3'-Bis(6-(4-methoxyphenoxy)hexyl-2,2'bithiophene-5,5'-diyl)bis(4,4,5,5-tetramethyl-1,3,2-dioxaborolane) (1.04 g, $1.25 \mathrm{mmol}$ ), 2-bromo-3-(6-(4-methoxyphenoxy)hexyl)thiophene $(0.991 \mathrm{~g}, 2.68 \mathrm{mmol}), \mathrm{K}_{2} \mathrm{CO}_{3}(1.16 \mathrm{~g}$, $8.4 \mathrm{mmol}$ ) and PEPPSI-IPr (94 mg) were placed in a Schlenk tube and vacuum-argon cycles were applied. Toluene $(15 \mathrm{~mL})$ and methanol $(15 \mathrm{~mL})$ were added through the septum and the reaction mixture was heated at $90{ }^{\circ} \mathrm{C}$ overnight. After cooling to room temperature the reaction mixture was diluted with dichloromethane $(25 \mathrm{~mL})$ and washed with water. The organic layer was dried with $\mathrm{MgSO}_{4}$, filtered and evaporated. The crude product was purified by column chromatography $\left(\mathrm{Al}_{2} \mathrm{O}_{3}\right.$, hexane/THF, $\left.4: 1\right)(0.42 \mathrm{~g}, 30 \%) .{ }^{1} \mathrm{H}$ NMR $\left(400 \mathrm{MHz}, d_{2^{-}}\right.$ $\left.\mathrm{CD}_{2} \mathrm{Cl}_{2}\right) \delta \mathrm{ppm} 7.18\left(\mathrm{~d}, J=5.1,2 \mathrm{H}, \mathrm{E}^{5}\right), 7.02\left(\mathrm{~s}, 2 \mathrm{H}, \mathrm{F}^{3}\right), 6.95(\mathrm{~d}$, $\left.J=5.5,2 \mathrm{H}, \mathrm{E}^{4}\right), 6.78(\mathrm{~s}, 8 \mathrm{H},-\mathrm{Ph}), 6.76(\mathrm{~s}, 8 \mathrm{H},-\mathrm{Ph}), 3.87-3.81$ $\left(\mathrm{m}, 8 \mathrm{H}, \mathrm{Hex}^{6}\right), 3.72\left(\mathrm{~s}, 12 \mathrm{H},-\mathrm{OCH}_{3}\right), 2.80\left(\mathrm{t}, J=7.8,4 \mathrm{H}, \mathrm{Hex}^{1}\right)$, $2.59\left(\mathrm{t}, J=7.8,4 \mathrm{H}, \mathrm{Hex}^{1}\right), 1.75-1.61\left(\mathrm{~m}, 16 \mathrm{H}, \mathrm{Hex}^{2}+\mathrm{Hex}^{5}\right)$, 1.46-1.39 (m, 16H, $\left.\operatorname{Hex}^{3}+\mathrm{Hex}^{4}\right) .{ }^{13} \mathrm{C}$ NMR (101 MHz, $d_{2}-$ $\left.\mathrm{CD}_{2} \mathrm{Cl}_{2}\right) \delta$ ppm 154.25, 153.85, 143.37, 140.11, 136.57, 131.12, $130.77,128.76,128.00,124.20,115.82,115.04,69.04,56.13$, 32.16, 31.20, 29.84, 29.72, 26.44. IR (DRIFT), $\mathrm{cm}^{-1} 3105(\mathrm{w})$, $3074(\mathrm{w}), 3047(\mathrm{w}), 2997$ (w), 2935 (s), 2858 (s), 1512 (s), 1466 (m), 1439 (w), 1389 (w), 1288 (m), 1242 (s), 1215 (s), 1180 (m), 1157 (w), $1111(\mathrm{~m}), 1068(\mathrm{~m}), 1041$ (s), $987(\mathrm{w}), 941(\mathrm{w})$, $922(\mathrm{w}), 825(\mathrm{~s}), 741(\mathrm{~m}), 721(\mathrm{~m}), 687(\mathrm{w}), 652(\mathrm{w}), 525(\mathrm{~m})$. HRMS found $m / z: 1155.49656\left[\mathrm{M}^{+} \mathrm{H}\right]^{+}, \mathrm{C}_{68} \mathrm{H}_{83} \mathrm{O}_{8} \mathrm{~S}_{4}$ requires: 1155.49653.

$5,5^{\prime \prime \prime}-\left(3,4^{\prime}, 3^{\prime \prime}, 3^{\prime \prime \prime}-\right.$ Tetra(6-(4-methoxyphenoxy)hexyl)-2, $2^{\prime}: 5^{\prime}, 2^{\prime \prime}: 5^{\prime \prime}, 2^{\prime \prime \prime}-$ quaterthiophene-5, $5^{\prime \prime \prime}$-diyl $)$ bis $(4,4,5,5$-tetramethyl-1,3,2dioxaborolane). 3,4',3",3'"'-Tetra(6-(4-methoxyphenoxy)hexyl)$2,2^{\prime}: 5^{\prime}, 2^{\prime \prime}: 5^{\prime \prime}, 2^{\prime \prime \prime}$-quaterthiophene (0.42 g, $\left.0.36 \mathrm{mmol}\right)$, dtbpy $(13 \mathrm{mg})$ and $\left([\operatorname{Ir}(\mathrm{OMe})(\mathrm{COD})]_{2}\right)(15 \mathrm{mg})$ were placed in a tube and vacuum-argon cycles were applied. Tetrahydrofuran (10 $\mathrm{mL})$, hexane $(10 \mathrm{~mL})$ and HBpin (0.2 mL, $0.176 \mathrm{~g}$, $1.38 \mathrm{mmol}$ ) were added and the reaction mixture was heated at $50{ }^{\circ} \mathrm{C}$ for 2 days. After opening the vessel the reaction mixture was diluted with water and stirred for an hour. Then the product was extracted with dichloromethane, dried with 
$\mathrm{MgSO}_{4}$, filtered and evaporated. The product was used in the following synthesis without purification $(0.48 \mathrm{~g}, 94 \%) .{ }^{1} \mathrm{H}$ NMR (400 MHz, $\left.d_{2}-\mathrm{CD}_{2} \mathrm{Cl}_{2}\right) \delta \mathrm{ppm} 7.43\left(\mathrm{~s}, 2 \mathrm{H}, \mathrm{C}^{4}\right), 7.09(\mathrm{~s}, 2 \mathrm{H}$, $\left.\mathrm{D}^{3}\right), 6.78(\mathrm{~s}, 8 \mathrm{H},-\mathrm{Ph}), 6.76(\mathrm{~s}, 8 \mathrm{H},-\mathrm{Ph}), 3.87-3.81(\mathrm{~m}, 8 \mathrm{H}$, $\mathrm{Hex}^{6}$ ), $3.72\left(\mathrm{~s}, 12 \mathrm{H},-\mathrm{OCH}_{3}\right), 2.81\left(\mathrm{t}, J=8.0,4 \mathrm{H}, \mathrm{Hex}^{1}\right), 2.60(\mathrm{t}$, $\left.J=7.6,4 \mathrm{H}, \mathrm{Hex}^{1}\right), 1.75-1.60\left(\mathrm{~m}, 16 \mathrm{H}, \mathrm{Hex}^{2}+\mathrm{Hex}^{5}\right), 1.48-1.40$ $\left(\mathrm{m}, 16 \mathrm{H}, \mathrm{Hex}^{3}+\mathrm{Hex}^{4}\right), 1.34$ (s, 24H, $-\mathrm{CH}_{3}$ pinacol ester). ${ }^{13} \mathrm{C}$ NMR (101 MHz, $\left.d_{2}-\mathrm{CD}_{2} \mathrm{Cl}_{2}\right) \delta \mathrm{ppm} 154.22,153.86,143.53$, 141.23, 138.16, 136.51, 131.09, 129.23, 128.37, 115.83, 115.04, $84.74,68.32,56.13,30.92,29.89,26.42,26.15,25.14,24.93 .{ }^{11} \mathrm{~B}$ NMR $\left(128,3 \mathrm{MHz}, d_{2}-\mathrm{CD}_{2} \mathrm{Cl}_{2}\right) \delta$ ppm 22.39.

$3,4^{\prime}, 3^{\prime \prime}, 3^{\prime \prime \prime}$-Tetra(6-(4-methoxyphenoxy)hexyl)-5, 5'"'-bis$\left(2,2^{\prime}: 6^{\prime}, 2^{\prime \prime}\right.$-terpyridin-4'-yl)-2,2':5',2":5", $2^{\prime \prime \prime}$-quaterthiophene Q2457-A. 5,5'"'-(3,4',3",3'"'-Tetra(6-(4-methoxyphenoxy)hexyl)$2,2^{\prime}: 5^{\prime}, 2^{\prime \prime}: 5^{\prime \prime}, 2^{\prime \prime \prime}$-quaterthiophene-5, 5"'-diyl)bis(4,4,5,5-tetramethyl-1,3,2-dioxaborolane) (0.45 g, $0.32 \mathrm{mmol}), \quad$ Brtpy (0.215 g, $0.69 \mathrm{mmol}), \mathrm{K}_{2} \mathrm{CO}_{3}(0.40 \mathrm{~g}, 2.89 \mathrm{mmol})$ and PEPPSI-IPr (32 mg) were placed in a Schlenk tube and vacuum and three vacuum-argon cycles were applied. The reaction mixture was heated to $90{ }^{\circ} \mathrm{C}$ overnight. After cooling to room temperature the mixture was diluted with dichloromethane $(40 \mathrm{~mL})$ and washed with water $(3 \times 200 \mathrm{~mL})$. The organic layer was dried with $\mathrm{MgSO}_{4}$, filtered and evaporated to obtain the crude product. The product was purified by column chromatography $\left(\mathrm{Al}_{2} \mathrm{O}_{3}\right.$, hexane/THF, $\left.3: 2\right)$. Orange solid $(0.17 \mathrm{~g}, 33 \%)$. ${ }^{1} \mathrm{H}$ NMR $\left(400 \mathrm{MHz}, d_{2}-\mathrm{CD}_{2} \mathrm{Cl}_{2}\right) \delta \mathrm{ppm} 8.74\left(\mathrm{~m}, 4 \mathrm{H}, \mathrm{A}^{6}\right), 8.70(\mathrm{~s}$, $\left.4 \mathrm{H}, \mathrm{B}^{3}\right), 8.67\left(\mathrm{~m}, 4 \mathrm{H}, \mathrm{A}^{3}\right), 7.91\left(\mathrm{td}, J_{1}=7.7, J_{2}=2.1,4 \mathrm{H}, \mathrm{A}^{4}\right)$, $7.67\left(\mathrm{~s}, 2 \mathrm{H}, \mathrm{C}^{4}\right), 7.40-7.37\left(\mathrm{~m}, 4 \mathrm{H}, \mathrm{A}^{5}\right), 7.19\left(\mathrm{~s}, 2 \mathrm{H}, \mathrm{D}^{4}\right)$, 6.80-6.72 (m, 16H, -Ph), 3.90-3.83 (m, 8H, Hex $\left.{ }^{6}\right), 3.69(\mathrm{~s}, 6 \mathrm{H}$, $\left.-\mathrm{OCH}_{3}\right), 3.66\left(\mathrm{~s}, 6 \mathrm{H},-\mathrm{OCH}_{3}\right), 2.89\left(\mathrm{t}, J=7.8,4 \mathrm{H}, \mathrm{Hex}^{1}\right), 2.66(\mathrm{t}$, $\left.J=7.8,4 \mathrm{H}, \operatorname{Hex}^{1}\right), 1.80-1.69\left(\mathrm{~m}, 16 \mathrm{H}, \mathrm{Hex}^{2}+\mathrm{Hex}^{5}\right), 1.45-1.38$ $\left(\mathrm{m}, 16 \mathrm{H}, \mathrm{Hex}^{3}+\mathrm{Hex}^{4}\right) \cdot{ }^{13} \mathrm{C} \mathrm{NMR}\left(101 \mathrm{MHz}, d_{2}-\mathrm{CD}_{2} \mathrm{Cl}_{2}\right) \delta \mathrm{ppm}$ $156.71,156.41,154.23$, 153.85, 149.74, 143.72, 143.37, 141.35, $139.47,137.42,136.23,133.28,129.58,129.34,128.46,124.58$, $121.62,116.88,115.83,115.03,69.06,56.09,31.06,29.92$, 29.70, 26.50, 26.42. IR (DRIFT), $\mathrm{cm}^{-1} 3063$ (w), 3009 (w), 2935 (s), $2854(\mathrm{~m}), 1601$ (m), 1581 (s), 1566 (s), 1508 (s), 1462 (s), 1400 (w), 1288 (w), 1238 (w), 1180 (w), 1149 (w), 1107 (m), 1072 (w), 1038 (s), 991 (w), 883 (w), 825 (m), 795 (m), $744(\mathrm{~m}), 679$ $(\mathrm{w}), 656(\mathrm{~m}), 633(\mathrm{w}), 621(\mathrm{w}), 525(\mathrm{w})$. HRMS found $\mathrm{m} / \mathrm{z}$ : 1617.65658 $\left[\mathrm{M}^{+} \mathrm{H}\right]^{+}, \mathrm{C}_{98} \mathrm{H}_{101} \mathrm{O}_{8} \mathrm{~N}_{6} \mathrm{~S}_{4}$ requires: 1617.65582 .

\section{General procedure for bromination of A-unimers}

A unimer was dissolved in dichloromethane (to a concentration of $c a .0 .02 \mathrm{M}$ ), the solution was then cooled in an ice bath and $\mathrm{BBr}_{3}$ was added (excess). After 4 hours of stirring the cooling bath was removed and the solution was poured into water. The mixture was carefully neutralized with a saturated solution of $\mathrm{K}_{2} \mathrm{CO}_{3}$. Then the product was extracted with dichloromethane, dried with $\mathrm{MgSO}_{4}$, filtered off and evaporated to obtain the desired product.

3,3"'-Di(6-bromohexyl)-5, 5"'-bis(2,2':6', 2"-terpyridin-4'-yl)2,2':5',2":5", 2'"'-quaterthiophene Q27-Br. Red solid $(90 \%) .{ }^{1} \mathrm{H}$ NMR (300 MHz, $\left.d-\mathrm{CDCl}_{3}\right) \delta$ ppm 8.75-8.79 (m, 4H, $\left.\mathrm{A}^{6}\right)$, 8.64-8.69 (m, 8H, A $\left.\mathrm{A}^{3}+\mathrm{B}^{3}\right), 7.89\left(\mathrm{td}, J_{1}=7.8, J_{2}=1.7,4 \mathrm{H}, \mathrm{A}^{4}\right)$, $7.65\left(\mathrm{~s}, 2 \mathrm{H}, \mathrm{C}^{4}\right), 7.38\left(\mathrm{ddd}, J_{1}=7.8, J_{2}=4.5, J_{3}=1.3,4 \mathrm{H}, \mathrm{A}^{5}\right)$, $7.21\left(\mathrm{~d}, J=3.6,2 \mathrm{H}, \mathrm{D}^{3}\right.$ or $\left.\mathrm{D}^{4}\right), 7.16\left(\mathrm{~d}, J=3.9,2 \mathrm{H}, \mathrm{D}^{4}\right.$ or $\left.\mathrm{D}^{3}\right)$, $3.45\left(\mathrm{t}, J=6.9,4 \mathrm{H}, \mathrm{Hex}^{6}\right), 2.88\left(\mathrm{t}, J=7.9,4 \mathrm{H}, \mathrm{Hex}^{1}\right), 1.99-1.73$ $\left(\mathrm{m}, 12 \mathrm{H}, \mathrm{Hex}^{2}+\mathrm{Hex}^{4}+\mathrm{Hex}^{5}\right), 1.57-1.45$ (m, $\left.4 \mathrm{H}, \mathrm{Hex}^{3}\right) \cdot{ }^{13} \mathrm{C}$ NMR (101 MHz, $\left.d-\mathrm{CDCl}_{3}\right) \delta \mathrm{ppm} 155.97,155.94,149.08$, $142.88,140.52$, 139.25, 137.08, 136.93, 134.97, 132.53, 128.82, $126.91,124.22,123.94,121.37,116.59,33.92,32.71,30.32$, 29.51, 28.69, 28.03. IR (DRIFT), $\mathrm{cm}^{-1} 3063$ (m), 3012 (w), 2931 (m), 2858 (m), 1601 (s), 1585 (s), 1566 (s), 1543 (m), 1466 (s), 1404 (s), 1385 (m), 1265 (w), 1122 (w), 1095 (w), 1072 (w), 1045 (w), 1018 (w), $991(\mathrm{w}), 883(\mathrm{~m}), 845$ (m), 791 (s), 741 (m), 660 $(\mathrm{w}), 621$ (w). HRMS found $m / z: 1117.14218 \quad\left[\mathrm{M}^{+} \mathrm{H}\right]^{+}$, $\mathrm{C}_{58} \mathrm{H}_{51} \mathrm{~N}_{6} \mathrm{Br}_{2} \mathrm{~S}_{4}$ requires: 1117.14193.

4',3"-Di(6-bromohexyl-5,5'"'-bis(2,2':6',2"-terpyridine-4'-yl)$2,2^{\prime}: 5^{\prime}, 2^{\prime \prime}: 5^{\prime \prime}, 2^{\prime \prime \prime}$-quaterthiophene Q45-Br. Orange solid (87\%). ${ }^{1} \mathrm{H} \mathrm{NMR}\left(400 \mathrm{MHz}, d-\mathrm{CDCl}_{3}\right) \delta \mathrm{ppm} 8.76\left(\mathrm{dd}, J_{1}=5.2, J_{2}=1.2\right.$, $\left.4 \mathrm{H}, \mathrm{A}^{3}\right), 8.70\left(\mathrm{~s}, 4 \mathrm{H}, \mathrm{B}^{3}\right), 8.67\left(\mathrm{~d}, J=7.9,4 \mathrm{H}, \mathrm{A}^{6}\right), 7.89\left(\mathrm{td}, J_{1}=\right.$ $\left.7.8, J_{2}=1.8,4 \mathrm{H}, \mathrm{A}^{4}\right), 7.73\left(\mathrm{~d}, J=3.9,2 \mathrm{H}, \mathrm{C}^{4}\right), 7.38\left(\mathrm{~m}, 4 \mathrm{H}, \mathrm{A}^{5}\right)$, $7.17\left(\mathrm{~s}, 2 \mathrm{H}, \mathrm{D}^{4}\right), 3.41\left(\mathrm{t}, J=6.9,4 \mathrm{H}, \mathrm{Hex}^{6}\right), 2.60(\mathrm{t}, J=7.3,4 \mathrm{H}$, $\left.\operatorname{Hex}^{1}\right), 1.72-1.61\left(\mathrm{~m}, 8 \mathrm{H}, \mathrm{Hex}^{2}+\mathrm{Hex}^{5}\right), 1.49-1.36\left(\mathrm{~m}, 8 \mathrm{H}, \mathrm{Hex}^{3}\right.$ $\left.+\mathrm{Hex}^{4}\right) .{ }^{13} \mathrm{C}$ NMR (101 MHz, $\left.d-\mathrm{CDCl}_{3}\right) \delta \mathrm{ppm} 156.11,155.97$, 149.14, 143.35, 142.97, 140.41, 138.80, 136.87, 127.96, 126.65, $125.81,124.66,123.94,123.37,121.32,116.67,33.91,32.70$, 30.44, 28.90, 28.49, 27.98. IR (DRIFT), $\mathrm{cm}^{-1} 3063$ (m), 3011 (m), 2932 (s), $2856(\mathrm{~m}), 1775(\mathrm{w}), 1655$ (w), 1599 (s), 1582 (s), 1567 (s), 1551 (s), 1509 (w), 1466 (s), 1438 (m), 1400 (s), 1378 (w), $1362(\mathrm{~m}), 1301(\mathrm{w}), 1292(\mathrm{w}), 1266(\mathrm{~m}), 1235(\mathrm{~m}), 1182(\mathrm{w})$, 1148 (w), 1126 (m), 1096 (m), 1065 (m), 1042 (m), 1011 (s), 989 (m), $903(\mathrm{w}), 877(\mathrm{~m}), 860(\mathrm{~m}), 848(\mathrm{~m}), 825(\mathrm{~m}), 791(\mathrm{~s}), 772$ (s), $745(\mathrm{~s}), 732(\mathrm{~s}), 680(\mathrm{~m}), 659(\mathrm{~m}), 633(\mathrm{~m}), 622(\mathrm{~m}), 584(\mathrm{w})$, 564 (m), 537 (m), 497 (m), 468 (m), 452 (w), 439 (w), 404 (m). HRMS found $m / z$ : $1117.14240\left[\mathrm{M}^{+} \mathrm{H}\right]^{+}, \mathrm{C}_{58} \mathrm{H}_{51} \mathrm{~N}_{6} \mathrm{Br}_{2} \mathrm{~S}_{4}$ requires: 1117.14193.

$3,4^{\prime}, 3^{\prime \prime}, 3^{\prime \prime \prime}-$ Tetra(6-bromohexyl)-5, 5"'-bis(2,2':6',2"-terpyridin$4^{\prime}-$ yl)-2,2':5',2":5",2'"'-quaterthiophene Q2457-Br. Red solid (95\%). ${ }^{1} \mathrm{H}$ NMR (400 MHz, $\left.d_{2}-\mathrm{CD}_{2} \mathrm{Cl}_{2}\right) \delta \mathrm{ppm} 8.74\left(\mathrm{~m}, 4 \mathrm{H}, \mathrm{A}^{6}\right.$ ), $8.71\left(\mathrm{~s}, 4 \mathrm{H}, \mathrm{B}^{3}\right), 8.68\left(\mathrm{~m}, 4 \mathrm{H}, \mathrm{A}^{3}\right), 7.92(\mathrm{td}, J=7.8, J=7.8, J=$ $\left.1.8,4 \mathrm{H}, \mathrm{A}^{4}\right), 7.69\left(\mathrm{~s}, 2 \mathrm{H}, \mathrm{C}^{4}\right), 7.40\left(\mathrm{ddd}, J=7.8, J=4.6,4 \mathrm{H}, \mathrm{A}^{5}\right)$, $7.19\left(\mathrm{~s}, 2 \mathrm{H}, \mathrm{D}^{4}\right), 3.46-3.41\left(\mathrm{~m}, 8 \mathrm{H}, \mathrm{Hex}^{6}\right), 2.90\left(\mathrm{~m}, 4 \mathrm{H}, \mathrm{Hex}^{1}\right)$, 2.66 (m, 4H, Hex ${ }^{1}$ ), 1.92-1.69 (m, 16H, Hex $^{2}+$ Hex $^{5}$ ), 1.55-1.47 $\left(\mathrm{m}, 16 \mathrm{H}, \mathrm{Hex}^{3}+\mathrm{Hex}^{4}\right) \cdot{ }^{13} \mathrm{C} \mathrm{NMR}\left(101 \mathrm{MHz}, d_{2}-\mathrm{CD}_{2} \mathrm{Cl}_{2}\right) \delta \mathrm{ppm}$ 156.29 , 155.97, 149.32, 143.22, 142.97, 140.85, 139.19, 137.0, $135.89,132.87,129.14,128.95,128.06,124.22$, 121.29, 116.53, 34.32, 33.00, 30.55, 29.71, 28.75, 28.22. IR (DRIFT), $\mathrm{cm}^{-1} 3062$ (m), 3012 (m), 2930 (s), 2855 (s), 1731 (w), $1656(\mathrm{w}), 1598$ (s), 1582 (s), 1567 (s), 1543 (m), 1466 (s), 1453 (s), 1437 (m), 1401 (s), $1382(\mathrm{~m}), 1335(\mathrm{w}), 1278(\mathrm{w}), 1265(\mathrm{~m}), 1236(\mathrm{w}), 1204(\mathrm{w})$, 1192 (w), 1145 (w), $1124(\mathrm{w}), 1094(\mathrm{~m}), 1071$ (m), 1042 (m), $1014(\mathrm{~m}), 990(\mathrm{~m}), 971(\mathrm{w}), 936(\mathrm{w}), 883(\mathrm{~m}), 865(\mathrm{w}), 847(\mathrm{~m})$, $837(\mathrm{~m}), 820(\mathrm{~m}), 791(\mathrm{~s}), 773(\mathrm{~m}), 743(\mathrm{~s}), 730(\mathrm{~s}), 712(\mathrm{w}), 676$ (w), $660(\mathrm{~s}), 633(\mathrm{~m}), 622(\mathrm{~m}), 564(\mathrm{~m}), 540(\mathrm{w}), 500(\mathrm{~m}), 467$ $(\mathrm{w}), 403(\mathrm{~m})$. HRMS found $\mathrm{m} / \mathrm{z}: 1441.15190\left[\mathrm{M}^{+} \mathrm{H}\right]^{+}$, $\mathrm{C}_{70} \mathrm{H}_{73} \mathrm{~N}_{6} \mathrm{Br}_{4} \mathrm{~S}_{4}$ requires: 1441.15076.

\section{General procedure for quaternization of Br-unimers}

A unimer was dissolved in toluene (to a concentration of $c a$. 6.5 $\mathrm{mM}$ ) and the flask was flushed with argon. Triethyl- 
phosphine $\left(\mathrm{PEt}_{3}\right)$ was added as $1 \mathrm{M}$ solution in THF (ca. 20 eq.) and the reaction was heated to $110{ }^{\circ} \mathrm{C}$ for 4 days during which the quaternized product gets precipitated from the solution. After cooling to room temperature the product was filtered and washed with toluene and diethylether. The desired product was dried in vacuo.

$6,6^{\prime}-\left[5,5^{\prime \prime \prime}-\operatorname{Bis}\left(2,2^{\prime}: 6^{\prime}, 2^{\prime \prime}\right.\right.$-terpyridine-4'-yl $)-\left(2,2^{\prime}: 5^{\prime}, 2^{\prime \prime}: 5^{\prime \prime}, 2^{\prime \prime \prime}-\right.$ quaterthiophen-3,3"'-diyl)]-bis(hexan-1,1'-diyl triethylphosphonium) bromide Q27-P $\mathbf{P}^{+}$. Dark red solid $(74 \%) .{ }^{1} \mathrm{H}$ NMR $\left(400 \mathrm{MHz}, d_{4}-\mathrm{CD}_{3} \mathrm{OD}\right) \delta \mathrm{ppm} 8.60(\mathrm{dd}, J=5.0, J=1.4,4 \mathrm{H}$, $\left.\mathrm{A}^{6}\right), 8.44\left(\mathrm{~d}, J=7.9,4 \mathrm{H}, \mathrm{A}^{3}\right), 8.29\left(\mathrm{~s}, 4 \mathrm{H}, \mathrm{B}^{3}\right), 7.89\left(\mathrm{td}, J_{1}=7.7\right.$, $\left.J_{2}=1.8,4 \mathrm{H}, \mathrm{A}^{4}\right), 7.47\left(\mathrm{~s}, 2 \mathrm{H}, \mathrm{C}^{4}\right), 7.39-7.45\left(\mathrm{~m}, 4 \mathrm{H}, \mathrm{A}^{5}\right), 7.12(\mathrm{~d}$, $J=3.6,2 \mathrm{H}, \mathrm{D}^{3}$ or $\left.\mathrm{D}^{4}\right), 7.08\left(\mathrm{~d}, J=3.9,2 \mathrm{H}, \mathrm{D}^{4}\right.$ or $\left.\mathrm{D}^{3}\right), 2.78-2.87$ $\left(\mathrm{m}, 4 \mathrm{H}, \mathrm{Hex}^{1}\right), 2.09-2.35\left(\mathrm{~m}, 20 \mathrm{H}, \mathrm{P}-\mathrm{CH}_{2}+\mathrm{Hex}^{5}+\mathrm{Hex}^{6}\right)$, 1.69-1.83 (m, 8H, $\left.\operatorname{Hex}^{2}+\mathrm{Hex}^{3}\right), 1.10-1.34\left(\mathrm{~m}, 22 \mathrm{H}, \mathrm{P}-\mathrm{CH}_{3}+\right.$ $\left.\mathrm{Hex}^{4}\right)$. Due to the low solubility of this compound we were not able to obtain the ${ }^{13} \mathrm{C}$ NMR spectrum in a sufficient quality. ${ }^{31} \mathrm{P}$ NMR (121.42 $\left.\mathrm{MHz}, d_{4}-\mathrm{CD}_{3} \mathrm{OD}\right) \delta \mathrm{ppm}$ 38.93. IR (DRIFT), $\mathrm{cm}^{-1} 3061(\mathrm{~m}), 3012(\mathrm{w}), 2976(\mathrm{~m}), 2933(\mathrm{~m}), 2861(\mathrm{~m}), 1599$ (m), 1582 (s), 1567 (m), 1545 (m), 1535 (w), 1466 (m), 1454 (m), 1402 (m), 1387 (w), 1292 (w), 1267 (w), 1200 (w), 1146 (w), 1125 (m), $1096(\mathrm{~m}), 1072(\mathrm{~m}), 1048(\mathrm{~m}), 1016(\mathrm{~m}), 989(\mathrm{~m}), 969(\mathrm{w})$, $882(\mathrm{~m}), 837(\mathrm{w}), 791(\mathrm{~s}), 743(\mathrm{~s}), 731(\mathrm{~m}), 680(\mathrm{~m}), 660(\mathrm{~s}), 622$ (m), $567(\mathrm{~m}), 553(\mathrm{~m}), 491(\mathrm{~m}), 468(\mathrm{~m}), 407$ (m). HRMS found $m / z: \quad 597.23970 \quad\left[\mathrm{M}^{+} \mathrm{H}\right]^{2+}, \mathrm{C}_{70} \mathrm{H}_{80} \mathrm{~N}_{6} \mathrm{P}_{2} \mathrm{~S}_{4} \quad z=2$ requires: 597.23958 .

$6,6^{\prime}-\left[5,5^{\prime \prime \prime}-\operatorname{Bis}\left(2,2^{\prime}: 6^{\prime}, 2^{\prime \prime}-\right.\right.$ terpyridine-4'-yl $)-\left(2,2^{\prime}: 5^{\prime}, 2^{\prime \prime}: 5^{\prime \prime}, 2^{\prime \prime \prime}-\right.$ quaterthiophen-4', $3^{\prime \prime}$-diyl)]-bis(hexan-1,1'-diyl triethylphosphonium) bromide Q45-P'. Red solid (95\%). ${ }^{1} \mathrm{H}$ NMR $\left(400 \mathrm{MHz}, d_{4}-\mathrm{CD}_{3} \mathrm{OD}\right) \delta \mathrm{ppm} 8.55-8.60\left(\mathrm{~m}, 4 \mathrm{H}, \mathrm{A}^{3}\right), 8.43\left(\mathrm{dd}, J_{1}\right.$ $\left.=7.9, J_{2}=1.1,4 \mathrm{H}, \mathrm{A}^{6}\right), 8.33\left(\mathrm{~s}, 4 \mathrm{H}, \mathrm{B}^{3}\right), 7.85-7.91\left(\mathrm{~m}, 4 \mathrm{H}, \mathrm{A}^{4}\right)$, $7.55\left(\mathrm{~d}, J=3.8,2 \mathrm{H}, \mathrm{C}^{4}\right), 7.39\left(\mathrm{ddd}, J_{1}=7.5, J_{2}=4.7, J_{3}=1.4,4 \mathrm{H}\right.$, $\left.\mathrm{A}^{5}\right), 7.23\left(\mathrm{~s}, 2 \mathrm{H}, \mathrm{D}^{4}\right), 7.13-7.16\left(\mathrm{~m}, 2 \mathrm{H}, \mathrm{C}^{3}\right), 2.56-2.64(\mathrm{~m}, 4 \mathrm{H}$, $\left.\mathrm{Hex}^{1}\right), 2.07-2.21\left(\mathrm{~m}, 20 \mathrm{H}, \mathrm{P}-\mathrm{CH}_{2}+\mathrm{Hex}^{5}+\mathrm{Hex}^{6}\right), 1.60-1.72(\mathrm{~m}$, $\left.8 \mathrm{H}, \mathrm{Hex}^{2}+\mathrm{Hex}^{3}\right), 1.07-1.20\left(\mathrm{~m}, 22 \mathrm{H}, \mathrm{P}-\mathrm{CH}_{3}+\mathrm{Hex}^{4}\right) .{ }^{13} \mathrm{C} \mathrm{NMR}$ (101 MHz, $\left.d_{4}-\mathrm{CD}_{3} \mathrm{OD}\right) \delta \mathrm{ppm} 156.81,156.46,149.98,144.93$, 144.07, 141.29, 140.29, 139.01, 138.11, 129.48, 128.51, 127.55, 126.29, 125.77, 122.94, 117.29, 31.88, 31.67, 30.26, 29.96, 22.47 (d, $J=4.4), 18.5$ (d, $J=47.9), 12.44$ (d, $J=49.4), 5.92$ (d, $J=5.3$ ). ${ }^{31} \mathrm{P}$ NMR (121.42 MHz, $\left.d_{4}-\mathrm{CD}_{3} \mathrm{OD}\right) \delta \mathrm{ppm}$ 38.44. IR (DRIFT), $\mathrm{cm}^{-1} 3062$ (m), 3011 (m), 2975 (m), 2930 (s), 2858 (s), 1600 (s), 1583 (s), 1567 (s), 1551 (m), 1535 (m), 1466 (s), 1439 (m), 1400 (s), $1363(\mathrm{w}), 1324(\mathrm{w}), 1292(\mathrm{w}), 1267(\mathrm{~m}), 1234(\mathrm{~m}), 1179(\mathrm{w})$, 1147 (w), 1125 (m), 1096 (m), 1062 (m), 1046 (m), 1011 (m), $990(\mathrm{~m}), 969(\mathrm{w}), 880(\mathrm{~m}), 861(\mathrm{w}), 847$ (w), $791(\mathrm{~s}), 773(\mathrm{~s}), 742$ (m), $726(\mathrm{~m}), 682(\mathrm{~m}), 660(\mathrm{~m}), 623(\mathrm{~m}), 580(\mathrm{w}), 539(\mathrm{w}), 497$ (m), $470(\mathrm{~m}), 463(\mathrm{w}), 405(\mathrm{~m})$. HRMS found $\mathrm{m} / \mathrm{z}$ : 597.23959 $\left[\mathrm{M}^{+} \mathrm{H}\right]^{2+}, \mathrm{C}_{70} \mathrm{H}_{80} \mathrm{~N}_{6} \mathrm{P}_{2} \mathrm{~S}_{4} z=2$ requires: 597.23958 .

$6,6^{\prime}, 6^{\prime \prime}, 6^{\prime \prime \prime \prime}-\left[5,5^{\prime \prime \prime}-\operatorname{Bis}\left(2,2^{\prime}: 6^{\prime}, 2^{\prime \prime}\right.\right.$-terpyridine-4'-yl)-(2,2':5',2":5", $2^{\prime \prime \prime}-$ quaterthiophen-3,4',3", $3^{\prime \prime \prime}$-tetrayl)]tetra(hexan-1,1',1", $1^{\prime \prime \prime}$-tetrayl triethylphosphonium) bromide Q2457-P $\mathbf{P}^{+}$. Red solid (92\%). ${ }^{1} \mathrm{H}$ NMR (400 MHz, $\left.d_{4}-\mathrm{CD}_{3} \mathrm{OD}\right) \delta \mathrm{ppm} 8.67-8.41\left(\mathrm{~m}, 12 \mathrm{H}, \mathrm{A}^{6}+\right.$ $\left.\mathrm{A}^{3}+\mathrm{B}^{3}\right), 7.99-7.90\left(\mathrm{~m}, 4 \mathrm{H}, \mathrm{A}^{4}\right), 7.67\left(\mathrm{~s}, 2 \mathrm{H}, \mathrm{C}^{4}\right), 7.49-7.43(\mathrm{~m}$, $\left.4 \mathrm{H}, \mathrm{A}^{5}\right), 7.23\left(\mathrm{~s}, 2 \mathrm{H}, \mathrm{D}^{4}\right), 2.90-2.84\left(\mathrm{~m}, 4 \mathrm{H}, \mathrm{Hex}^{1}\right), 2.70-2.84(\mathrm{~m}$, $4 \mathrm{H}, \mathrm{Hex}^{1}$ ), 2.31-2.15 (m, 40H, P-CH $\left.\mathrm{CH}_{2}+\mathrm{Hex}^{5}+\mathrm{Hex}^{6}\right), 1.84-1.79$ $\left(\mathrm{m}, 16 \mathrm{H}, \mathrm{Hex}^{2}+\mathrm{Hex}^{3}\right), 1.31-1.10\left(\mathrm{~m}, 44 \mathrm{H}, \mathrm{P}-\mathrm{CH}_{3}+\mathrm{Hex}^{4}\right)$.
${ }^{13} \mathrm{C}$ NMR (101 MHz, $d_{4}$-CD $\left.3 \mathrm{OD}\right) \delta$ ppm 157.03, 156.58, 150.25, 144.59, 144.04, 142.02, 139.94, 138.92, 137.23, 134.15, 130.61, $129.97,129.05,125.69,122.83,117.39,31.91,31.31,30.15$, 22.55, 18.61 (d, $J=46.4), 13.94$ (d, $J=50.8), 12.56$ (d, $J=48.6$ ), $6.03(\mathrm{~m}) .{ }^{31} \mathrm{P}$ NMR (161.92 $\left.\mathrm{MHz}, d_{4}-\mathrm{CD}_{3} \mathrm{OD}\right) \delta \mathrm{ppm} 39.99$. IR (DRIFT), cm ${ }^{-1} 3444(\mathrm{~m}), 3055(\mathrm{w}), 2978(\mathrm{~m}), 2931(\mathrm{~s})$, 2854 (m), 1597 (m), 1581 (s), 1566 (m), 1466 (s), 1404 (m), 1269 (w), 1246 (w), 1200 (w), 1122 (w), 1095 (w), 1049 (m), $1018(\mathrm{w}), 991(\mathrm{w}), 887(\mathrm{w}), 845(\mathrm{w}), 795(\mathrm{~m}), 744(\mathrm{~m}), 660(\mathrm{~m})$, $621(\mathrm{w}), 509(\mathrm{w}), 471(\mathrm{w}), 455(\mathrm{w})$. HRMS found $\mathrm{m} / \mathrm{z}: 399.20815$ $\left[\mathrm{M}^{+} \mathrm{H}\right]^{4+}, \mathrm{C}_{94} \mathrm{H}_{132} \mathrm{~N}_{6} \mathrm{P}_{4} \mathrm{~S}_{4} z=4$ requires: 399.20812 .

\section{Acknowledgements}

This work was supported by the Czech Science Foundation (P108/12/1143), the Grant Agency of Charles University (project 64213) and the COST Action CM1302 (SIPS) European Network on Smart Inorganic Polymers.

\section{References}

1 E. Figgemeier, V. Aranyos, E. C. Constable, R. W. Handel, C. E. Housecroft, C. Risinger, A. Hagfeldt and E. Mukhtar, Inorg. Chem. Commun., 2004, 7, 117-121.

2 C. Houarner, E. Blart, P. Buvat and F. Odobel, Photochem. Photobiol. Sci., 2005, 4, 200-204.

3 C. Houarner-Rassin, E. Blart, P. Buvat and F. Odobel, J. Photochem. Photobiol., A, 2007, 186, 135-142.

4 S. Caramori, J. Husson, M. Beley, C. a. Bignozzi, R. Argazzi and P. C. Gros, Chem. - Eur. J., 2010, 16, 2611-2618.

5 K. W. Cheng, C. S. C. Mak, W. K. Chan, A. M. Ching NG and A. B. Djurišič, J. Polym. Sci., Part A: Polym. Chem., 2008, 46, 1305-1317.

6 V. Duprez and F. C. Krebs, Tetrahedron Lett., 2006, 47, 3785-3789.

7 A. Wild, F. Schlütter, G. M. Pavlov, C. Friebe, G. Festag, A. Winter, M. D. Hager, V. Cimrová, U. S. Schubert, V. Cimrova and U. S. Schubert, Macromol. Rapid Commun., 2010, 31, 868-874.

8 R. Siebert, A. Winter, M. Schmitt, J. Popp, U. S. Schubert and B. Dietzek, Macromol. Rapid Commun., 2012, 33, 481497.

9 P. D. Vellis, J. A. Mikroyannidis, C. Lo and C. Hsu, J. Polym. Sci., Part A: Polym. Chem., 2008, 46, 7702-7712.

10 X. Chen, Q. Zhou, Y. Cheng, Y. Geng, D. Ma, Z. Xie and L. Wang, J. Lumin., 2007, 126, 81-90.

11 X. Chen, L. Ma, Y. Cheng, Z. Xie and L. Wang, Polym. Int., 2007, 56, 648-654.

12 R. Siebert, A. Winter, B. Dietzek, U. S. Schubert and J. Popp, Macromol. Rapid Commun., 2010, 31, 883-888.

13 S. Etienne and M. Beley, Inorg. Chem. Commun., 2006, 9, 68-71.

14 L. D. Carlos, R. a. S. Ferreira, V. De Zea Bermudez and S. J. L. Ribeiro, Adv. Mater., 2009, 21, 509-534. 
15 M. Barboiu, Y.-M. Legrand, L. Prodi, M. Montalti, N. Zaccheroni, G. Vaughan, A. van der Lee, E. Petit and J.-M. Lehn, Eur. J. Inorg. Chem., 2009, 2009, 2621-2628.

16 S. Encinas, L. Flamigni, F. Barigelletti, E. C. Constable, C. E. Housecroft, E. R. Schofield, E. Figgemeier, D. Fenske, M. Neuburger, J. G. Vos and M. Zehnder, Chem. - Eur. J., 2002, 8, 137-150.

17 T. K. Sievers, A. Vergin, H. Möhwald, D. G. Kurth, A. Verging, H. Möhwald and D. G. Kurth, Langmuir, 2007, 23, 12179-12184.

18 G. Schwarz, I. Haßlauer and D. G. Kurth, Adv. Colloid Interface Sci., 2014, 207, 107-120.

19 F. S. Han, M. Higuchi and D. G. Kurth, Adv. Mater., 2007, 19, 3928-3931.

20 Y. Y. Chen, Y.-T. Tao and H.-C. Lin, Macromolecules, 2006, 39, 8559-8566.

21 A. Winter, C. Friebe, M. Chiper, M. D. Hager and U. S. Schubert, J. Polym. Sci., Part A: Polym. Chem., 2009, 3, 4083-4098.

22 A. Wild, A. Teichler, C.-L. Ho, X.-Z. Wang, H. Zhan, F. Schlütter, A. Winter, M. D. Hager, W.-Y. Wong and U. S. Schubert, J. Mater. Chem. C, 2013, 1, 1812-1822.

23 R. Siebert, Y. Tian, R. Camacho, A. Winter, A. Wild, A. Krieg, U. S. Schubert, J. Popp, I. G. Scheblykin and B. Dietzek, J. Mater. Chem., 2012, 22, 16041-16050.

24 Y. Y. Chen and H. C. Lin, J. Polym. Sci., Part A: Polym. Chem., 2007, 45, 3243-3255.

25 R. Dobrawa, M. Lysetska, P. Ballester, M. Grüne and F. Würthner, Macromolecules, 2005, 38, 1315-1325.

26 C. Ringenbach, A. De Nicola and R. Ziessel, J. Org. Chem., 2003, 68, 4708-4719.

27 S. C. Yu, C. C. Kwok, W. K. Chan and C. M. Che, Adv. Mater., 2003, 15, 1643-1647.

28 P. Bláhová, J. Zedník, I. Šloufová, J. Vohlídal and J. Svoboda, Soft Matter, 2014, 12, 214-229.

29 P. Štenclová-Bláhová, J. Svoboda, I. Šloufová and J. Vohlídal, Phys. Chem. Chem. Phys., 2015, 17, 1374313756.

30 J. Lehn, Prog. Polym. Sci., 2005, 30, 814-831.

31 J. W. Steed and J. L. Atwood, Supramolecular chemistry, John Wiley \& Sons, Ltd, 2nd edn, 2009.

32 A. Ciferri, Macromol. Rapid Commun., 2002, 23, 511-529.
33 J. Svoboda, P. Stenclova, F. Uhlík, J. Zedník and J. Vohlídal, Tetrahedron, 2011, 67, 75-79.

34 D. Bondarev, J. Zedník, I. Šloufová, A. Sharf, M. Procházka, J. Pfleger and J. Vohlídal, J. Polym. Sci., Part A: Polym. Chem., 2010, 48, 3073-3081.

35 C. G. Bochet, C. Piguet and A. F. Williams, Helv. Chim. Acta, 1993, 76, 372-384.

36 D. Rais, M. Menšík, P. Štenclová-Bláhová, J. Svoboda, J. Vohlídal and J. Pfleger, J. Phys. Chem. A, 2015, 119, 62036214.

37 I. Šloufová, B. Vlčková, M. Procházka, J. Svoboda and J. Vohlídal, J. Raman Spectrosc., 2014, 45, 338-348.

38 S. Kazim, J. Pfleger, K. Halašová, M. Procházka, D. Bondarev and J. Vohlídal, Eur. Phys. J.: Appl. Phys., 2011, 55, 23905.

39 P. S. Braterman, J.-I. Song and R. D. Peacock, Inorg. Chem., 1992, 31, 555-559.

40 F. Schlütter, A. Wild, A. Winter, M. D. Hager, A. Baumgaertel, C. Friebe and U. S. Schubert, Macromolecules, 2010, 43, 2759-2771.

41 T. Vitvarová, J. Zedník, M. Bláha, J. Vohlídal and J. Svoboda, Eur. J. Inorg. Chem., 2012, 2012, 3866-3874.

42 V. Stepanenko, M. Stocker, P. Müller, M. Büchner and F. Würthner, J. Mater. Chem., 2009, 19, 6816-6826.

43 R. A. Dobrawa, Synthesis and Characterization of Terpyridinebased Fluorescent Coordination Polymers, Bayerischer JuliusMaximilians-Universität, Würzburg, 2004.

44 J. N. Demas and B. A. DeGraft, Topics in Fluorescence Spectroscopy: Volume 4: Probe Design and Chemical Sensing, 1994.

45 R. Englman and J. Jortner, Mol. Phys., 1970, 18, 145-164.

46 R. Dobrawa and F. Würthner, J. Polym. Sci., Part A: Polym. Chem., 2005, 43, 4981-4995.

47 U. S. Schubert, H. Hofmeier and G. R. Newkome, Modern Terpyridine Chemistry, Wiley-VCH Verlag $\mathrm{GmbH}$, Weinheim, 2006.

48 R. Hogg and R. G. Wilkins, J. Chem. Soc., 1962, 341-350.

49 R. H. Holyer, C. D. Hubbard, S. F. A. Kettle and R. G. Wilkins, Inorg. Chem., 1966, 5, 622-625.

50 J. R. Winkler, C. Creutz and N. Sutin, J. Am. Chem. Soc., 1987, 109, 3470-3471.

51 J. Burgess, S. Radulović and F. Sánchez, Transition Met. Chem., 1987, 12, 529-536. 